\title{
Functional characterisation of phagocytes in the Pacific oyster Crassostrea gigas
}

\author{
Shuai Jiang ${ }^{1}$, Zhihao Jia ${ }^{1}$, Tao Zhang ${ }^{1}$, Lingling Wang ${ }^{1,2}$, Limei Qiu ${ }^{1}$, Jinsheng Sun ${ }^{3}$, Linsheng Song ${ }^{\text {Corresp }}$ \\ ${ }^{1}$ Key laboratory of Experimental Marine Biology, Institute of Oceanology, Chinese Academy of Sciences, Qingdao, Shandong, China \\ 2 Key Laboratory of Mariculture \& Stock Enhancement in North China's Sea, Ministry of Agriculture, Dalian Ocean University, Dalian, Liaoning, China \\ 3 Tianjin Key Laboratory of Animal and Plant Resistance, Tianjin Normal University, Tianjin, 300387, China \\ Corresponding Author: Linsheng Song
}

Email address: Ishsong@qdio.ac.cn

Invertebrates lack canonical adaptive immunity and mainly rely on innate immune system to fight against pathogens. The phagocytes, which could engulf and kill microbial pathogens, are likely to be of great importance and have to undertake significant roles in invertebrate immune defense. In the present study, flow cytometry combined with histological and lectin staining was employed to characterise functional features of phagocytes in the Pacific oyster Crassostrea gigas. Based on the cell size and cellular contents, haemocytes were categorised into three cell types, i.e., granulocytes, semigranulocytes and agranulocytes. Agranulocytes with smaller cell volume and lower cytoplasmic-to-nuclear ratio did not show phagocytic activity, while semigranulocytes and agranulocytes exhibited larger cell volume, higher cytoplasmic-to-nuclear ratio and phagocytic activity. In addition, granulocytes with higher side scatter (SSC) exhibited higher phagocytic activity than that of semigranulocytes. When $\beta$-integrin and lectin-like receptors were blocked by RGD tripeptide and carbohydrates, respectively, the phagocytic activity of both granulocytes and semigranulocytes was significantly inhibited, indicating that $\beta$-integrin and certain lectin-like receptors were involved in phagocytosis towards microbes. Moreover, lipopolysaccharide but not peptidylglycan could enhance phagocytic activity of granulocytes and semigranulocytes towards Vibrio splendidus and Staphylococcus aureus. Lectin staining analysis revealed that Lycopersicon esculentum lectin (LEL), binding the epitope polylactosamine, was highly distributed on the extracellular cell surface of phagocytes, and could be utilized as a potential molecular marker to differentiate phagocytes from non-phagocytic haemocytes. The results, collectively, provide knowledge on the functional characters of oyster phagocytes, which would contribute to deep investigation of cell typing and cellular immunity in bivalves. 
1

2

3

4

$5 \quad$ Shuai Jiang ${ }^{\mathrm{a}}$, Zhihao Jia ${ }^{\mathrm{a}}$, Tao Zhang ${ }^{\mathrm{a}}$, Lingling Wang ${ }^{\mathrm{a}}$, Limei Qiu ${ }^{\mathrm{a}}$, Jinsheng Sun ${ }^{\mathrm{c}}$, Linsheng

6

7

8

9

10

11

12

13

14

15

16

17

\section{Functional characterisation of phagocytes in the Pacific oyster \\ Crassostrea gigas}

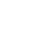

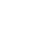

6

$$
\text { Song }{ }^{\mathrm{b}, *}
$$

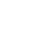

8

a Key laboratory of Experimental Marine Biology, Institute of Oceanology, Chinese Academy of Sciences, Qingdao, 266071, China.

${ }^{\mathrm{b}}$ Key Laboratory of Mariculture \& Stock enhancement in North China’s Sea, Ministry of Agriculture, Dalian Ocean University, Dalian 116023, China.

c Tianjin Key Laboratory of Animal and Plant Resistance, Tianjin Normal University, Tianjin, 300387, China.

5

* Address correspondence to: Linsheng Song

Dalian Ocean University, No. 52 Heishijiao street, Dalian 116023, China.

Tel: +86 41184763173 ; Fax: +86 41184763306

Email address: 1shsong@dlou.edu.cn 


\section{ABSTRACT}

23 Invertebrates lack canonical adaptive immunity and mainly rely on innate immune system to

24 fight against pathogens. The phagocytes, which could engulf and kill microbial pathogens, are

likely to be of great importance and have to undertake significant roles in invertebrate immune

defense. In the present study, flow cytometry combined with histological and lectin staining was

employed to characterise functional features of phagocytes in the Pacific oyster Crassostrea

gigas. Based on the cell size and cellular contents, haemocytes were categorised into three cell

types, i.e., granulocytes, semigranulocytes and agranulocytes. Agranulocytes with smaller cell volume and lower cytoplasmic-to-nuclear ratio did not show phagocytic activity, while semigranulocytes and agranulocytes exhibited larger cell volume, higher cytoplasmic-to-nuclear ratio and phagocytic activity. In addition, granulocytes with higher side scatter (SSC) exhibited higher phagocytic activity than that of semigranulocytes. When $\beta$-integrin and lectin-like receptors were blocked by RGD tripeptide and carbohydrates, respectively, the phagocytic activity of both granulocytes and semigranulocytes was significantly inhibited, indicating that $\beta$ integrin and certain lectin-like receptors were involved in phagocytosis towards microbes. Moreover, lipopolysaccharide but not peptidylglycan could enhance phagocytic activity of granulocytes and semigranulocytes towards Vibrio splendidus and Staphylococcus aureus. Lectin staining analysis revealed that Lycopersicon esculentum lectin (LEL), binding the epitope polylactosamine, was highly distributed on the extracellular cell surface of phagocytes, and could be utilized as a potential molecular marker to differentiate phagocytes from non-phagocytic haemocytes. The results, collectively, provide knowledge on the functional characters of oyster 
43 phagocytes, which would contribute to deep investigation of cell typing and cellular immunity in 44 bivalves.

45

46 


\section{INTRODUCTION}

48 Phagocytosis, the uptake and digestion of exogenous particles, is an ancient, evolutionarily

49

50

51

52

53

54 conserved cellular process, which plays important roles in the pathogen killing and clearance as well as the food uptake (Aderem \& Underhill 1999; Greenberg \& Grinstein 2002; Henneke \& Golenbock 2004). In mammals, professional phagocytes, such as macrophages and neutrophils, are particularly responsible for the killing and the clearance of pathogens, and for initiating signaling pathways to that trigger potent immune responses (Kaufmann \& Dorhoi 2016). More importantly, some phagocytes named antigen-presenting cells (APCs) are well known not only for their potent phagocytic activity but also for the antigen presentation activity, which has been deemed as the bridge between innate immunity and adaptive immunity (Delamarre et al. 2005). Invertebrates, which lack the canonical adaptive immunity based on $\mathrm{B}$ and $\mathrm{T}$ lymphocytes, mainly rely on the innate immune system to fight against pathogens (Little et al. 2005; Milutinovic \& Kurtz 2016). Compared with the phagocytes in vertebrates, invertebrate phagocytes are likely to be of great importance and have even major roles in immune defense (Robb et al. 2014). In previous studies, haemocytes have been typed into various cell subpopulations in several invertebrates, and some subpopulations have been confirmed to be in charge of phagocytosis. For instance, granulocytes in Crassostrea virginica were found to be active in phagocytosis (Goedken \& De Guise 2004). In Drosophila melanogaster, plasmatocytes were specifically responsible for the ingestion of microorganisms, while lamellocytes and crystal cells were involved in encapsulation and melanisation respectively (Lemaitre \& Hoffmann 2007). Recently, the capture and engulfment of bacteria by circulating or fixed phagocytes have also 
68

69

been reported in several invertebrates (Le Grand et al. 2011; Soderhall 2010).

The Pacific oyster Crassostrea gigas is an important species for physiological ecology as well as economical resource (Zhang et al. 2012). In the present study, flow cytometry combined with histological staining was employed to categorise the haemocytes based on their morphological features; the phagocytic activities of different cell populations were also determined. The phagocytic modulation effects of $\beta$-integrin, lectin-like receptors (LLRs), lipopolysaccharide (LPS) and peptidylglycan (PGN) were investigated, and the potential glycan markers distinguishing phagocytes from non-phagocytic cells were screened in order to better understand phagocytosis in oyster innate immune defense.

\section{MATERIALS AND METHODS}

\section{Animal rearing and manipulation}

Oysters, $10-15 \mathrm{~cm}$ in length and 150-200 $\mathrm{g}$ in weight, were collected from a farm in Qingdao, Shandong Province, China, and acclimated in aerated seawater at $18{ }^{\circ} \mathrm{C}$ for two weeks prior to use. All the experiments were conducted according to the regulations of local and central government. The animal experiments were approved by the local animal care and use committee.

\section{Preparation of haemocytes from $C$. gigas}

Haemolymph was withdrawn using a syringe equipped with a needle $(0.9 \times 25 \mathrm{~mm})$ from the pericardial cavity of adult $C$. gigas specimens after the shells were carefully opened, and mixed immediately with prechilled antiaggregant ACD-A $(0.1 \mathrm{~mol} / 1$ trisodium citrate, $0.11 \mathrm{~mol} / \mathrm{l}$ dextrose and $71 \mathrm{mmol} / 1$ citric acid monohydrate) at a volume ratio of 7: 1 . Haemocytes $(\sim 1 \times$ 
89

90

91

92

$10^{6}$ haemocytes per oyster) were pelleted at $800 \mathrm{~g}$, at $4{ }^{\circ} \mathrm{C}$ for $10 \mathrm{~min}$, and washed twice with modified Leibovitz L15 medium (supplemented with $0.54 \mathrm{~g} / 1 \mathrm{KCl}, 0.6 \mathrm{~g} / \mathrm{CaCl}_{2}, 1 \mathrm{~g} / 1 \mathrm{MgSO}_{4}$, $3.9 \mathrm{~g} / 1 \mathrm{MgCl}_{2}, 20.2 \mathrm{~g} / \mathrm{l} \mathrm{NaCl}, 100$ units/ml penicillin $\mathrm{G}, 40 \mu \mathrm{g} / \mathrm{l}$ gentamycin, $100 \mu \mathrm{g} / \mathrm{ml}$ streptomycin, $0.1 \mu \mathrm{g} / \mathrm{ml}$ amphotericin B and 10\% fetal bovine serum) (Novas et al. 2007). The Haemocytes from 3-5 individuals were pooled together as one sample, and $1 \times 10^{6}$ haemocytes were prepared and stored on ice to reduce spontaneous aggregation. The cell viability was measured using the Trypan Blue exclusion assay (McCarthy et al. 2014).

\section{Phagocytosis assay and May-Grunwald Giemsa (MGG) staining}

For phagocytosis assay, haemocytes were incubated with Pichia pastoris at a ratio of 1:100 for $1 \mathrm{~h}$, and washed by modified L15 medium for three times. Haemocytes were plated onto glass slides to allow cell adhesion at $18{ }^{\circ} \mathrm{C}$ for $3 \mathrm{~h}$, and the glass slides were fixed with $100 \%$ methanol for 10 min. MGG was used to stain cells for another 10 min followed by PBS washing, and the cells on the slides were characterized by light microscopy according to their morphological features.

\section{Preparation of FITC-labeled microbes}

Vibrio splendidus was grown in $2216 \mathrm{E}$ media at $28^{\circ} \mathrm{C}$, at $220 \mathrm{rpm}$ for $12 \mathrm{~h}$. Escherichia coli, Staphylococcus aureus and Bacillus subtilis were grown in LB media at $37^{\circ} \mathrm{C}$, at $220 \mathrm{rpm}$ for 8 h. Pichia pastoris was grown in YPD media at $30^{\circ} \mathrm{C}$, at $220 \mathrm{rpm}$ for $24 \mathrm{~h}$. All the microbes were grown to mid-log phase and harvested by centrifugation at $6000 \mathrm{~g}$ for $15 \mathrm{~min}$. Cells were fixed with $4 \%$ paraformaldehyde (PFA) for 10 min, washed with $0.1 \mathrm{M} \mathrm{NaHCO}_{3}(\mathrm{pH} 9.0)$ for three times, and then mixed with $1 \mathrm{mg} / \mathrm{ml}$ FITC (Sigma-Aldrich) in $0.1 \mathrm{M} \mathrm{NaHCO}_{3}(\mathrm{pH} 9.0$ ) buffer at 
110

111

112

113

114

115

116

117

118

119

120

121

122

123

124

125

126

127

128

129

130

room temperature with continuous gentle stirring overnight. The FITC-labeled microbes were washed with PBS for three times to eliminate free FITC molecules.

\section{Flow cytometric analysis of haemocyte and its phagocytosis}

Haemocytes were collected and analyzed on a FACS Arial II flow cytometer (Becton Dickinson Biosciences). For morphological characterisation of haemocytes, forward scatter (FSC) combined with side scatter (SSC) analysis was performed to measure relative cell size and internal complexity of cells respectively. For phagocytosis analysis, FITC-labeled microbes and latex beads (Sigma-Aldrich) were incubated with haemocytes at a ratio of $100: 1$ at $18{ }^{\circ} \mathrm{C}$ for $1 \mathrm{~h}$. Cells were then washed by modified L15 medium three times, and Trypan Blue (1.2 mg/ml) was used to quench surface-bound FITC-labeled bacteria. FSC and FL1 channel detection was immediately performed to analyze the phagocytosis of FITC-labeled particles.

\section{RGD, carbohydrates and PAMPs treatments of haemocytes}

Haemocytes were incubated with Arg-Gly-Asp (RGD) tripeptide at $0.5 \mathrm{mg} / \mathrm{ml}$ for $1 \mathrm{~h}$ to block $\beta$-integrin, and incubated with different carbohydrates including glucose (Glu), fucose (Fuc), mannose (Man), lactose (Lac) and N-acetylglucosamine (GlcNAc) at $100 \mathrm{mM}$ for $1 \mathrm{~h}$ to block lectin like receptors (LLRs), respectively. For the LPS and PGN stimulations, haemocytes were incubated with LPS and PGN at 0.1 and $1 \mathrm{mg} / \mathrm{ml}$ for $1 \mathrm{~h}$, respectively. Cells were then washed with modified L15 medium for three times, followed by incubation with FITC-labeled microbes at a ratio of 1:100. Flow cytometry was performed to analyse the percentages of phagocytosing haemocytes.

Flow cytometric and confocal microscopic analysis of lectin staining 

ratio of $1: 100$ at $18{ }^{\circ} \mathrm{C}$ for $1 \mathrm{~h}$ followed by extensively washing, and then incubated with

FACSAria II). For microscopic analysis, haemocytes were collected and suspended in the cell culture medium at the concentration of $1 \times 10^{6}$ cells $/ \mathrm{ml}$. The cell suspension $(1.5 \mathrm{ml})$ was then added in cell culture dishes and incubated for $3 \mathrm{~h}$ to allow cell adhesion. Haemocytes were incubated for $1 \mathrm{~h}$ with FITC-labeled latex beads at a ratio of 1:100. Haemocytes were then fixed by $4 \%$ PFA at $4{ }^{\circ} \mathrm{C}$ for 15 min after washing with three times L-15 medium, and adding 5\% BSA and incubated at room temperature for $1 \mathrm{~h}$. PE-labeled LEL $(50 \mu \mathrm{g} / \mathrm{ml})$ was incubated with haemocytes at room temperature for another $1 \mathrm{~h}$ and washed three times with

PBS. Haemocytes were monitored and fluorescent images were taken using Carl Zeiss LSM 710 confocal microscope (Jena, Germany).

\section{Statistical analysis}

The one way ANOVA followed by Dunnett's multiple comparison test and Student's $t$ test were used for the comparisons between groups. Statistical analysis was performed with GraphPad Prism 5 software. The statistical significance was defined as $p<0.05$. 
152

153

154

155

156

157

158

159

160

161

162

163

164

165

166

167

168

169

170

171

172

\section{Morphological characters of the haemocytes from $C$. gigas}

Haemocytes collected from C. gigas were gated by light-scatter characteristics using flow cytometer, and May-Grunwald-Giemsa (MGG) staining was performed to characterize the cellular morphology of each subpopulation (Fig. 1A). Based on the forward scatter (FSC) and side scatter (SSC) intensity, haemocytes were divided into three subpopulations including agranulocytes, granulocytes and semigranulocytes. Agranulocytes were located at the lower left position on the light scatter chart with smaller size (approximate 5-8 $\mu \mathrm{m}$ ), clear cytoplasm and lower cytoplasmic-to-nuclear ratio. Granulocytes were located at the upper right position with larger cell size (approximate 10-14 $\mu \mathrm{m}$ ), abundant intracellular contents, and higher cytoplasmicto-nuclear ratio. Semigranulocytes were located at the lower right position with larger cell size (approximate 11-13 $\mu \mathrm{m}$ ), lower internal complexity, and higher cytoplasmic-to-nuclear ratio (Fig. 1A). In addition, most agranulocytes and granulocytes appeared approximately round-shaped on the glass slide, while some of semigranulocytes extended filopodia to explore the microenvironment and spread on the glass slide. A total of 10, 000 haemocytes were analyzed by flow cytometry, and the agranulocyte, granulocyte and semigranulocyte subpopulations comprised $46.2 \%, 31.4 \%$ and $19.6 \%$ of the total haemocytes, respectively (Fig. 1B).

\section{Morphological identification of phagocytes from $C$. gigas}

In order to gain a further observation of phagocytes, Pichia pastoris with large cell diameter was employed as exogenous particles to allow phagocytosis of haemocytes, and MGG staining was performed to characterize the histological features of phagocytes (Fig. 2A). Phagocytes exhibited larger cell diameter after phagocytosing (approximately 9-14 $\mu \mathrm{m}$ ) with higher 
173 cytoplasmic-to-nuclear ratio (engulfment of 4-7 fungal cells per phagocyte), while non174 phagocytic cells exhibited smaller cell size $(5-9 \mu \mathrm{m})$, and their nucleus almost filled the cell, 175 leaving a thin rim of cytoplasm. The morphological features of phagocytes were further 176 characterized by flow cytometric analysis (Fig. 2B), and these cells with engulfment of FITC177 labeled latex beads were featured with larger cell size (higher FSC value). The percentage of phagocytes in total haemocytes was calculated to be $8.86 \%$. The haemocytes with smaller cell size (lower FSC value) did not exhibit phagocytic capability towards FITC-labeled latex beads. Although the phagocytes ingesting yeast cells could be different from the haemocytes ingesting latex beads, the results collectively suggested that phagocytic haemocytes are probably represented by granulocytes and semigranulocytes, which possess larger cell size and higher cytoplasmic-to-nuclear ratio.

\section{Involvement of $\beta$-integrin in phagocytosis}

Phagocytes are in charge of phagocytizing exogenous particles, and the phagocytic capability of oyster haemocytes towards different microbes was further investigated by flow cytometric analysis. The percentages of the phagocytic haemocytes were $24.8 \%$ for E. coli (Fig. $3 \mathrm{~A}$ ), $8.2 \%$ for $V$. splendidus (Fig. 3B) and 14.7\% for S. aureus (Fig. 3C). Moreover, granulocytes exhibited higher phagocytic percentages than that of semigranulocytes, which were $38.7 \%$ and $19.1 \%$ for $E$. coli, $9.8 \%$ and $7.4 \%$ for $V$. splendidus, and $24.1 \%$ and $10.3 \%$ for $S$. aureus, respectively. The total percentages of the phagocytic haemocytes significantly decreased of $43.2 \%$ for E. coli (Fig. 3A), 39.6\% for $V$. splendidus (Fig. 3B) and $45.7 \%$ for $S$. aureus (Fig. 3C) after the incubation with RGD. Moreover, under the same conditions, the phagocytic percentages of granulocytes 
194 and semigranulocytes significantly decreased of $37.8 \%$ and $46.4 \%$ for E. coli, $35.1 \%$ and $47.8 \%$

195 for $V$. splendidus, $40.5 \%$ and $48.4 \%$ for $S$. aureus, respectively.

196 The involvement of lectin-like receptors in the phagocytosis of different microbes

197 The participation of LLRs in phagocytosis towards microbes was determined after the 198 incubation with Glucose (Glu), fucose (Fuc), mannose (Man), lactose (Lac) and N199 acetylglucosamine (GlcNAc), respectively. Fuc, Man and GlcNAc exhibited significantly 200 inhibitory effects on the phagocytosis of haemocytes towards $V$. splendidus with the percentages 201 of phagocytosing haemocytes decreased to $58.4 \%, 67.1 \%$ and $64.6 \%$, respectively, while Glu 202 and Lac did not show any significant inhibition on phagocytosis of total haemocytes towards $V$. splendidus (Fig. 4A). After the treatments with Fuc, Lac and GlcNAc, the percentages of phagocytosing haemocytes decreased to $73.4 \%, 75.5 \%$ and $72.2 \%$ in granulocytes (Fig. 4B), and the percentages of phagocytosing semigranulocytes decreased to $54.8 \%$ and $52.4 \%$ after Fuc and Man treatments, (Fig. 4C). In addition, Fuc, Man and GlcNAc exhibited inhibitory effects on the phagocytosis towards $S$. aureus in total haemocytes, and the percentages of phagocytosing haemocytes significantly decreased to $70.7 \%, 60.5 \%$ and $63.7 \%$, respectively, while the inhibitory effects of Glu and Lac on phagocytosis of total haemocytes towards $S$. aureus were much lower (Fig. 4D). The percentages of phagocytosing granulocytes towards $S$. aureus were also significantly decreased to $62.9 \%, 58.1 \%$ and $56.4 \%$ after Fuc, Man and GlcNAc treatment, respectively (Fig. 4E), and the percentages of phagocytosing semigranulocytes towards $S$. aureus decreased to $72.7 \%$ and $70.2 \%$ after Fuc and Man treatments (Fig. 4F).

\section{The enhancement of phagocytosis after LPS treatment}


percentages of phagocytosing haemocytes towards $V$. splendidus and $S$. aureus in the total

haemocytes, granulocytes or semigranulocytes after 0.01 and $0.1 \mathrm{mg} / \mathrm{ml} \mathrm{PGN} \mathrm{treatments,}$

respectively.

\section{Lycopersicon esculentum lectin exhibited high binding specificity to phagocytes}

In order to further characterize the molecular features of phagocytes, lectin staining was

performed to distinguish phagocytes from non-phagocytic cells (Fig. 6A). Cells positive to 
236 Conversely, the haemocytes positive to wheat germ agglutinin (WGA) and peanut agglutinin

237 (PNA) staining were not significantly associated with phagocytes. The percentages of PE-

$238 \mathrm{WGA}^{+} / \mathrm{FITC}^{-}$cells were even higher than that of $\mathrm{PE}-\mathrm{WGA}^{+} / \mathrm{FITC}^{+}$cells, indicating that WGA

239 exhibited binding activity to both phagocytes and non-phagocytic haemocytes (Fig. 6B, left).

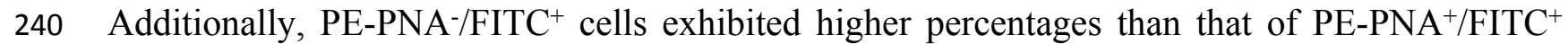

241 cells, suggesting that PNA preferred binding to non-phagocytic haemocytes rather than

242 phagocytes (Fig. 6B, middle). The results clearly indicated that LEL positive staining cells

243 exhibited higher accordance with phagocytes, while WGA and PNA staining exhibited much

244 lower binding specificity towards phagocytes and non-phagocytic cells.

245 The distribution of polylactosamine in oyster phagocytes

246 The LEL binding carbohydrate epitopes, including N-linked and O-linked polylactosamines,

247 are reported with at least three lactosamine repeats in Fig. 7A. The phagocyte-specific

248 distribution of polylactosamine was further confirmed by confocal microscopic analysis.

249 Polylactosamine, as indicated by PE-labeled LEL (red color), was highly distributed on the cell

250 membrane, and assembled to form a cap on one side of the phagocytes in the merge confocal

251 image (Fig. 7B, upper right panel). It was noted that polylactosamine also concentrated as

252 patches in cytoplasm of phagocytes. By contrast, there was no positive signal of LEL in non-

phagocytic haemocytes (Fig. 7B, lower right panel), indicating that polylactosamine probably not expressed in non-phagocytic cells. 
257

258

259

260

261

262

263

264

265

266

267

268

269

270

271

272

273

274

275

276

277

\section{DISCUSSION}

Phagocytes are in charge of phagocytosis, encapsulation and oxidative killing, and provide the main effectors to kill pathogens and sustain immune homeostasis (Pham et al. 2007). In previous studies, various criteria were applied to haemocyte classification in bivalve molluscs. For example, it was proposed to divide the haemocytes from C. gigas into several groups including basophilic and eosinophilic granulocytes, blast-like haemocytes and large basophilic agranular haemocytes (Bachere et al. 1988; Hine 1999). Different morphs of haemocytes of Crassostrea rhizophorae were proposed to correspond to different developmental stages of the same cell type, which accumulated or lost granules and complexity in response to environmental or microbial challenges (Rebelo Mde et al. 2013). Moreover, a granular population composed of basophilic and eosinophilic granulocytes in oysters was reported to possess phagocytic activity (Bachere et al. 2004). In the present study, we divided the oyster haemocytes into three cell subpopulations by flow cytometry based on cell size and intracellular contents: agranulocytes, granulocytes and semigranulocytes. Both granulocytes and semigranulocytes exhibited phagocytic activity towards FITC-labeled latex beads and different microbes, while the agranulocytes with smaller cell size did not exhibit phagocytic activity. In addition, the granulocytes exhibited higher phagocytic activity than that of semigranulocytes. It has been reported that the granules in oyster haemocytes were rich in antimicrobial peptides, which were reported to bound specifically to phagosomes and be rapidly released into the phagosomes/phagolysosomes to kill the phagocytosed microbial pathogens, suggesting a vital role of granulocyte in the clearance of pathogen (Gonzalez et al. 2007; Rosa et al. 2011). The classification of phagocytes into 
278

279

280

281

282

283

284

285

286

287

288

289

290

291

292

293

294

295

296

297

298

granulocytes and semigranulocytes could be helpful to further investigate the phagocytosis in the innate immune modulation and pathogen elimination of C. gigas.

Molecular markers have been proved to be extremely useful for cell typing in mammalian immune system, while the cell typing of haemocytes in invertebrates still needs to be elucidated (Kurucz et al. 2007; Le Foll et al. 2010). Even if the invertebrate haemocytes are of great heterogeneity, a relationship has been found between different molecular markers and the corresponding cellular functions. In Mytilus edulis, the small granules of the granulocytes were found to be HPA-positive, and the large granules of the granulocytes were of WGA positive, indicating that lectin staining could be applied in the cell typing (Pipe 1990). In Crassostrea virginica, haemocytes infected with Haplosporidium nelsoni (MSX) could be agglutinated by WGA and HPA, suggesting that haemocytes contained surface receptors resembling N-acetyl-Dglucosamine and $\alpha$-methylmannopyranoside (Kanaley \& Ford 1990). In Anopheles gambiae, only the granulocytes from individuals challenged by Plasmodium falciparum malaria could be stained by Lens culinaris agglutinin, whereas most (96\%) of naive granulocytes were negative and $4 \%$ were stained weakly $(p<0.0001)$ (Rodrigues et al. 2010). In the present study, the phagocytes could be separated from non-phagocytic cells based on the differential distribution of glycans by LEL staining. LEL exhibits high binding specificity towards polylactosamines with at least three lactosamine repeats, and has been widely used to discriminate different cell types (Togayachi et al. 2007). Most of the LEL positive haemocytes from C. gigas were phagocytes, suggesting the abundant distribution of polylactosamine glycans in phagocytes. Conversely the positive signals of WGA and PNA were observed in both phagocytes and non-phagocytic cells, 
299

300

301

302

303

304

305

306

307

308

309

310

311

312

313

314

315

316

317

318

319

indicating that there were no distribution differences of WGA- and PNA-binding epitopes between phagocytes and non-phagocytic cells in $C$. gigas.

Co-evolutionary arms races between pathogens and hosts, and the competitions are considered to be of immense importance in the evolution of living organisms (Akira et al. 2001; Akira et al. 2006). Integrins are required for cell-microorganism interaction and correct formation of phagosomes, and they play important roles in the phagocytosis (Ballarin et al. 2002; Oliva et al. 2008). In the present study, the blockage of $\beta$-integrin by RGD inhibited phagocytosis towards both Gram-negative and Gram-positive bacteria in granulocytes and semigranulocytes, indicating that $\beta$-integrin was extensively involved in the phagocytosis of oyster haemocytes. RGDcontaining peptides were reported to induce haemocyte apoptosis in C. gigas at the concentration of $3 \mathrm{mM}$ (Terahara et al. 2003; Terahara et al. 2005), which was much higher than that used in the present study, suggesting that lower concentration of RGD peptide could inhibit phagocytosis, while higher concentration of RGD peptide could induce cell apoptosis.

Lectins, typical pattern recognition receptors (PRRs), are involved in the pathogen recognition and phagocytosis. For example, a C-type lectin (CfLec-3) from Chlamys farreri with three carbohydrate-recognition domains (CRDs) could modulate haemocyte phagocytosis via binding to different PAMPs and microbes (Yang et al. 2015). The native lectin FcLec4 could bind to $\beta$ integrin to promote haemocytic phagocytosis in Fenneropenaeus chinensis (Wang et al. 2014).

17 Genes encoding lectin-like receptors (LLRs) are highly over-represented in oyster genome $(p<$ 0.0001) (Zhang et al. 2012). In the present study, the blockage of LLRs by Fuc, Man and GlcNAc exhibited an inhibitory effect on phagocytosis of total haemocytes towards $V$. 
320

321

322

323

324

325

326

327

328

329

330

331

332

333

334

335

336

337

338

339

340

splendidus and S. aureus, indicating that LLRs were involved in the recognition of different microbes and modulation of phagocytosis. However, Glu exhibited little inhibitory effect on the phagocytosis towards $V$. splendidus or S. aureus, suggesting that the Glu binding LLRs might not participate in the phagocytosis of the two bacteria.

PAMPs are important stimuli in the activation of immune responses (Iliev et al. 2005). LPS has been proved to act as an extremely strong stimulator of innate immunity in mammals (Alexander \& Rietschel 2001; Kawai \& Akira 2010). The extracellular membrane receptors, such as Toll-like receptor 4 (TLR4), could recognize LPS and initiate the rapid immuneactivation through an intracellular signaling pathway (Chu \& Mazmanian 2013; Shenoy et al. 2012; West et al. 2011). Moreover, various forms of $\beta$-glucans have been proved to possess a potential value in shrimp and fish aquaculture, as they could increase the numbers of circulating haemocytes, promote long-term activation of haemocytes and enhance the haemocytic aggregation (Anderson et al. 2011). In the present study, LPS stimulation substantially increased the phagocytic activity of both granulocytes and semigranulocytes towards $V$. splendidus and $S$. aureus, while PGN stimulation had no effect on the phagocytosis. It is noteworthy that a number of Gram-negative bacteria, including $V$. splendidus, have been identified to be important aquaculture pathogens, which could cause massive mortalities of oysters (Garnier et al. 2008; Richards et al. 2015). The enhancement of phagocytic activity towards microbial pathogens under LPS stimulation contributed to better understand the modulation of phagocytosis in oysters, and suggested the potential application in oyster aquaculture.

In conclusion, the present study showed that $C$. gigas haemocytes can be categorised into three 
341 cell types including granulocytes, semigranulocytes and agranulocytes. The phagocytic capacity 342 of granulocytes and semigranulocytes towards different microbes was determined, and the $\beta$ 343 integrin and certain LLRs were found to play important roles in the phagocytosis of granulocytes 344 and semigranulocytes. In addition, LPS but not PGN could significantly enhance the phagocytic 345 activities. Moreover, LEL binding epitope polylactosamine was highly distributed on the 346 extracellular cell surface of phagocytes, which could represent a potential molecular marker to 347 differentiate phagocytes from non-phagocytic haemocytes.

\section{ACKNOWLEDGEMENTS}

350 The authors would like to thank Dahai Gao (Institute of Oceanology, Chinese Academy of

351 Sciences) for the support in the flow cytometry and Sheng Wang (Sun Yat-sen University) for 352 the help in the cell staining. 
Aderem A, and Underhill DM. 1999. Mechanisms of phagocytosis in macrophages. Annual review of immunology 17:593-623.

Akira S, Takeda K, and Kaisho T. 2001. Toll-like receptors: critical proteins linking innate and acquired immunity. Nature Immunology 2:675-680.

Akira S, Uematsu S, and Takeuchi O. 2006. Pathogen recognition and innate immunity. Cell 124:783-801. Journal of Endotoxin Research 7:167-202.

Anderson RS, Ozbay G, Kingsley DH, and Strauss MA. 2011. Oyster hemocyte mobilization and increased adhesion activity after beta-glucan administration. Journal of Shellfish Research 30:635-641.

Bachere E, Chagot D, and Grizel H. 1988. Separation of Crassostrea gigas hemocytes by density gradient centrifugation and counterflow centrifugal elutriation. Developmental and Comparative Immunology 12:549-559.

Bachere E, Gueguen Y, Gonzalez M, de Lorgeril J, Garnier J, and Romestand B. 2004. Insights into the anti-microbial defense of marine invertebrates: the penaeid shrimps and the oyster Crassostrea gigas. Immunological Reviews 198:149-168.

Ballarin L, Scanferla M, Cima F, and Sabbadin A. 2002. Phagocyte spreading and phagocytosis in the compound ascidian Botryllus schlosseri: evidence for an integrin-like, RGD- 

26:345-354.

377 Chu HT, and Mazmanian SK. 2013. Innate immune recognition of the microbiota promotes hostmicrobial symbiosis. Nature Immunology 14:668-675.

Delamarre L, Pack M, Chang H, Mellman I, and Trombetta ES. 2005. Differential lysosomal proteolysis in antigen-presenting cells determines antigen fate. Science 307:1630-1634.

Garnier M, Labreuche Y, and Nicolas JL. 2008. Molecular and phenotypic characterization of Vibrio aestuarianus subsp. francensis subsp. nov., a pathogen of the oyster Crassostrea gigas. Systematic and Applied Microbiology 31:358-365. mechanisms. Fish and Shellfish Immunology 16:539-552. Immunology 14:136-145.

Henneke P, and Golenbock DT. 2004. Phagocytosis, innate immunity, and host-pathogen Molecular characterization of two isoforms of defensin from hemocytes of the oyster Crassostrea gigas. Developmental and Comparative Immunology 31:332-339.

Greenberg S, and Grinstein S. 2002. Phagocytosis and innate immunity. Current Opinion in 9:367-385. 
(Oncorhynchus mykiss) mononuclear phagocytes by different pathogen associated molecular pattern (PAMP) bearing agents. Molecular Immunology 42:1215-1223.

398

399

400

401

402

403

404

405

406

407

408

409

410

411

412

413

414

415

416

Kanaley SA, and Ford SE. 1990. Lectin binding characteristics of haemocytes and parasites in the oyster, Crassostrea virginica, infected with Haplosporidium nelsoni (MSX). Parasite Immunology 12:633-646.

Kaufmann SH, and Dorhoi A. 2016. Molecular Determinants in Phagocyte-Bacteria Interactions. Immunity 44:476-491.

Kawai T, and Akira S. 2010. The role of pattern-recognition receptors in innate immunity: update on Toll-like receptors. Nature Immunology 11:373-384.

Kurucz E, Vaczi B, Markus R, Laurinyecz B, Vilmos P, Zsamboki J, Csorba K, Gateff E, Hultmark D, and Ando I. 2007. Definition of Drosophila hemocyte subsets by cell-type specific antigens. Acta Biologica Hungarica 58 Suppl:95-111.

Le Foll F, Rioult D, Boussa S, Pasquier J, Dagher Z, and Leboulenger F. 2010. Characterisation of Mytilus edulis hemocyte subpopulations by single cell time-lapse motility imaging. Fish and Shellfish Immunology 28:372-386.

Le Grand F, Kraffe E, Marty Y, Donaghy L, and Soudant P. 2011. Membrane phospholipid composition of hemocytes in the Pacific oyster Crassostrea gigas and the Manila clam Ruditapes philippinarum. Comparative Biochemistry and Physiology a-Molecular and Integrative Physiology 159:383-391.

Lemaitre B, and Hoffmann J. 2007. The host defense of Drosophila melanogaster. Annual Review of Immunology 25:697-743. 
417 Little TJ, Hultmark D, and Read AF. 2005. Invertebrate immunity and the limits of mechanistic immunology. Nature Immunology 6:651-654.

419

420

421

422

423

424

425

426

427

428

429

430

431

432

433

434

435

436

437

McCarthy M, O'Halloran J, O'Brien NM, and van Pelt FF. 2014. Does the marine biotoxin okadaic acid cause DNA fragmentation in the blue mussel and the pacific oyster? Marine Environmental Research 101:153-160.

Milutinovic B, and Kurtz J. 2016. Immune memory in invertebrates. Seminars in Immunology 28:328-342.

Novas A, Barcia R, and Ramos-Martinez JI. 2007. Nitric oxide production by haemocytes from Mytilus galloprovincialis shows seasonal variations. Fish and Shellfish Immunology 23:886-891.

Oliva CR, Swiecki MK, Griguer CE, Lisanby MW, Bullard DC, Turnbough CL, and Kearney JF. 2008. The integrin Mac-1 (CR3) mediates internalization and directs Bacillus anthracis spores into professional phagocytes. Proceedings of the National Academy of Sciences of the United States of America 105:1261-1266.

Pham LN, Dionne MS, Shirasu-Hiza M, and Schneider DS. 2007. A specific primed immune response in Drosophila is dependent on phagocytes. Plos Pathogens 3. ARTN e26

Pipe RK. 1990. Differential binding of lectins to hemocytes of the mussel Mytilus edulis. Cell and Tissue Research 261:261-268.

Rebelo Mde F, Figueiredo Ede S, Mariante RM, Nobrega A, de Barros CM, and Allodi S. 2013. New insights from the oyster Crassostrea rhizophorae on bivalve circulating hemocytes. PLoS One 8:e57384. 
438 Richards GP, Watson MA, Needleman DS, Church KM, and Hase CC. 2015. Mortalities of 439 Eastern and Pacific oyster larvae caused by the pathogens Vibrio coralliilyticus and Vibrio tubiashii. Applied and Environmental Microbiology 81:292-297.

Robb CT, Dyrynda EA, Gray RD, Rossi AG, and Smith VJ. 2014. Invertebrate extracellular phagocyte traps show that chromatin is an ancient defence weapon. Nature Communications 5:4627.

Rodrigues J, Brayner FA, Alves LC, Dixit R, and Barillas-Mury C. 2010. Hemocyte differentiation mediates innate immune memory in Anopheles gambiae mosquitoes. Science 329:1353-1355.

Rosa RD, Santini A, Fievet J, Bulet P, Destoumieux-Garzon D, and Bachere E. 2011. Big defensins, a diverse family of antimicrobial peptides that follows different patterns of expression in hemocytes of the oyster Crassostrea gigas. PLoS One 6. ARTN e25594

Shenoy AR, Wellington DA, Kumar P, Kassa H, Booth CJ, Cresswell P, and MacMicking JD. 2012. GBP5 Promotes NLRP3 inflammasome assembly and immunity in mammals. Science 336:481-485.

Soderhall K. 2010. Invertebrate immunity. Preface. Advances in Experimental Medicine and Biology 708:vii-ix.

Terahara K, Takahashi KG, and Mori K. 2003. Apoptosis by RGD-containing peptides observed in hemocytes of the Pacific oyster, Crassostrea gigas. Developmental and Comparative Immunology 27:521-528. 
459

460

461

462

463

464

465

466

467

468

469

470

471

472

473

474

475

476

477

478

479

following cell-adhesion mediated by integrin-like molecules. Comparative Biochemistry and Physiology a-Molecular \& Integrative Physiology 141:215-222.

Togayachi A, Kozono Y, Ishida H, Abe S, Suzuki N, Tsunoda Y, Hagiwara K, Kuno A, Ohkura T, Sato N, Sato T, Hirabayashi J, Ikehara Y, Tachibana K, and Narimatsu H. 2007. Polylactosamine on glycoproteins influences basal levels of lymphocyte and macrophage activation. Proceedings of the National Academy of Sciences of the United States of America 104:15829-15834.

Wang XW, Zhao XF, and Wang JX. 2014. C-type lectin binds to beta-integrin to promote hemocytic phagocytosis in an invertebrate. Journal of Biological Chemistry 289:24052414.

West AP, Shadel GS, and Ghosh S. 2011. Mitochondria in innate immune responses. Nature Reviews Immunology 11:389-402.

Yang J, Huang M, Zhang H, Wang L, Wang H, Qiu L, and Song L. 2015. CfLec-3 from scallop: an entrance to non-self recognition mechanism of invertebrate C-type lectin. Scientific Reports 5:10068.

Zhang G, Fang X, Guo X, Li L, Luo R, Xu F, Yang P, Zhang L, Wang X, Qi H, Xiong Z, Que H, Xie Y, Holland PW, Paps J, Zhu Y, Wu F, Chen Y, Wang J, Peng C, Meng J, Yang L, Liu J, Wen B, Zhang N, Huang Z, Zhu Q, Feng Y, Mount A, Hedgecock D, Xu Z, Liu Y, Domazet-Loso T, Du Y, Sun X, Zhang S, Liu B, Cheng P, Jiang X, Li J, Fan D, Wang W, Fu W, Wang T, Wang B, Zhang J, Peng Z, Li Y, Li N, Chen M, He Y, Tan F, Song X, Zheng Q, Huang R, Yang H, Du X, Chen L, Yang M, Gaffney PM, Wang S, Luo L, She 

and complexity of shell formation. Nature 490:49-54. 
484

485

486

487

488

489

490

491

\section{Figure legends}
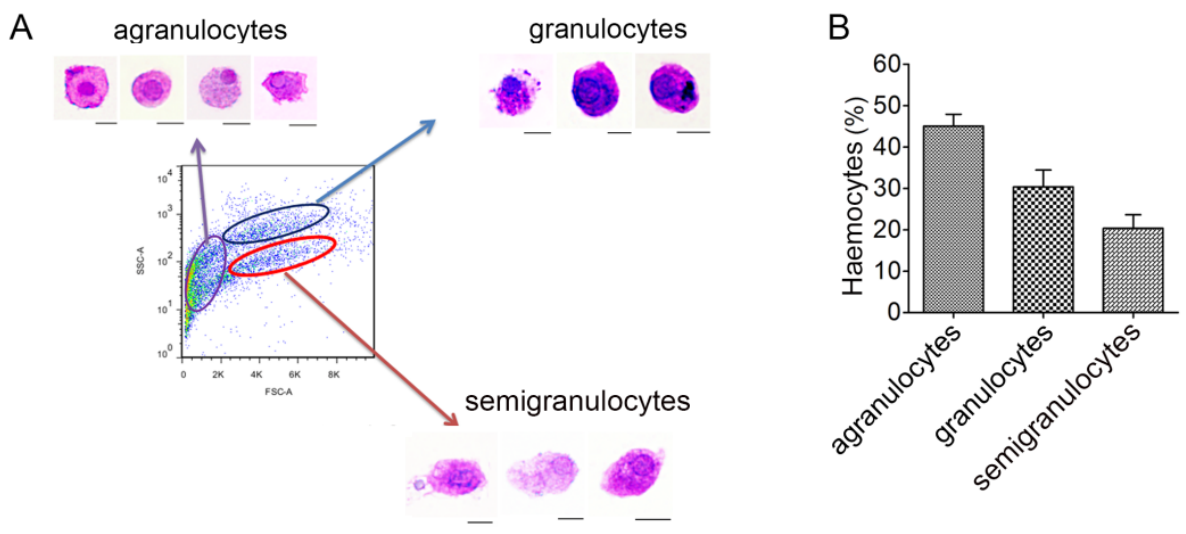

Fig. 1. Flow cytometric analysis and May-Grunwald-Giemsa (MGG) staining of haemocytes from C. gigas. (A) Haemocytes were categorized into different subpopulations by flow cytometry followed by MGG staining analysis. Bar: $5 \mu \mathrm{m}$. (B) The percentages of each subpopulation were calculated with statistically analysis. Results are means \pm S.E.M. $(n=6)$. 


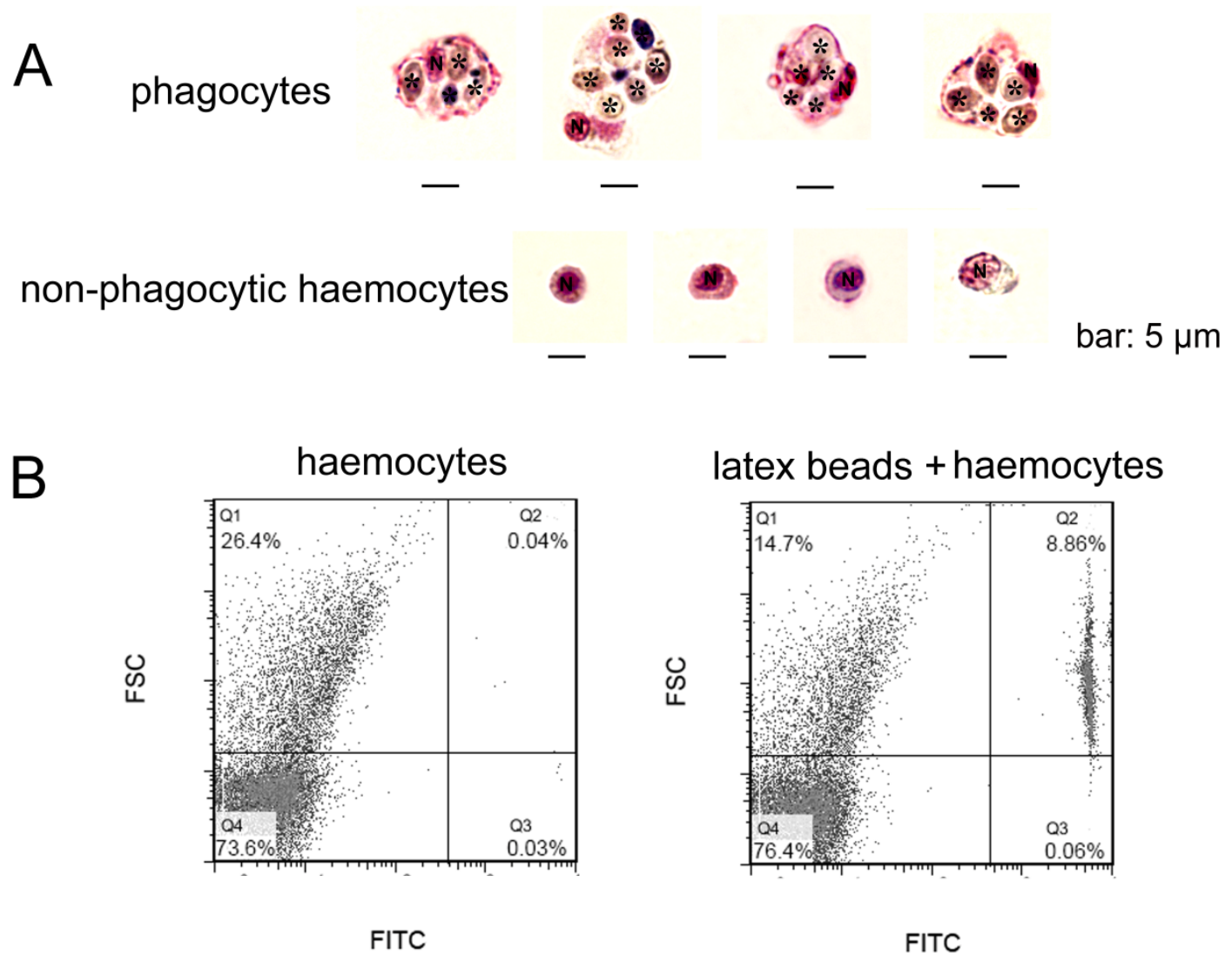

492

Fig. 2. Morphological identification of phagocytes from C. gigas. (A) Haemocytes were

494 incubated with fungal cells Pichia pastoris to allow phagocytosis, followed by MGG staining

495 and microscopic analysis. Fungal cells are indicated with asterisks, N stands for cell nucleus. Bar:

496 $5 \mu \mathrm{m}$. (B) Haemocytes pre-incubated with FITC-labeled latex beads (2 $\mu \mathrm{m}$ diameter) and

497 analyzed by flow cytometry. 

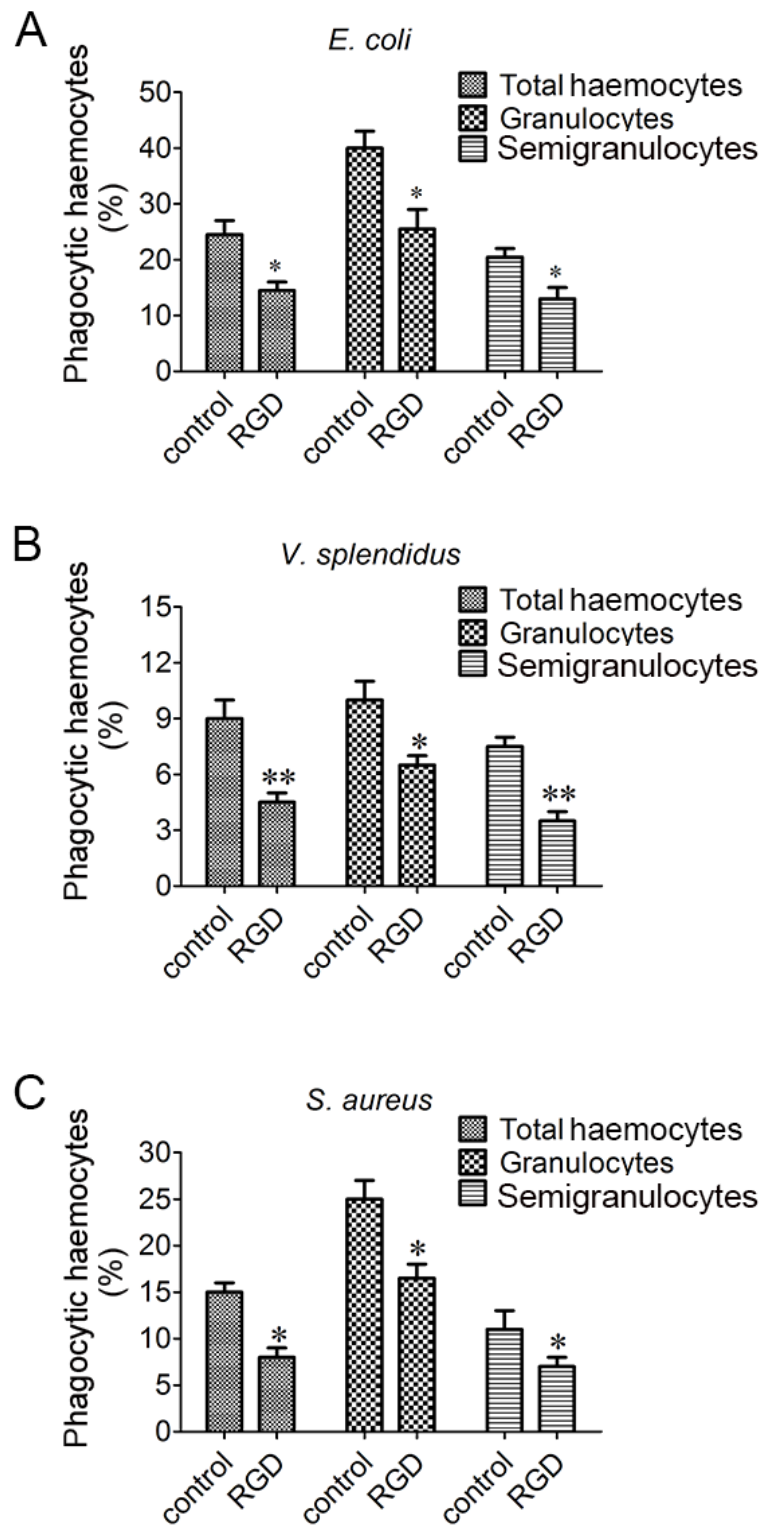

499

500 Fig. 3. Involvement of $\beta$-integrin in phagocytosis towards different microbes. Haemocytes were

501 treated with or without RGD tripeptide, and the phagocytic activities towards $E$. coli, $V$.

502 splendidus and $S$. aureus were determined by flow cytometry. Phagocytic percentages were shown respectively $(\mathrm{A}, \mathrm{B}$ and $\mathrm{C})$. Results are means \pm S.D. $(\mathrm{n}=6),{ }^{*} p<0.05,{ }^{*} p<0.01$. 

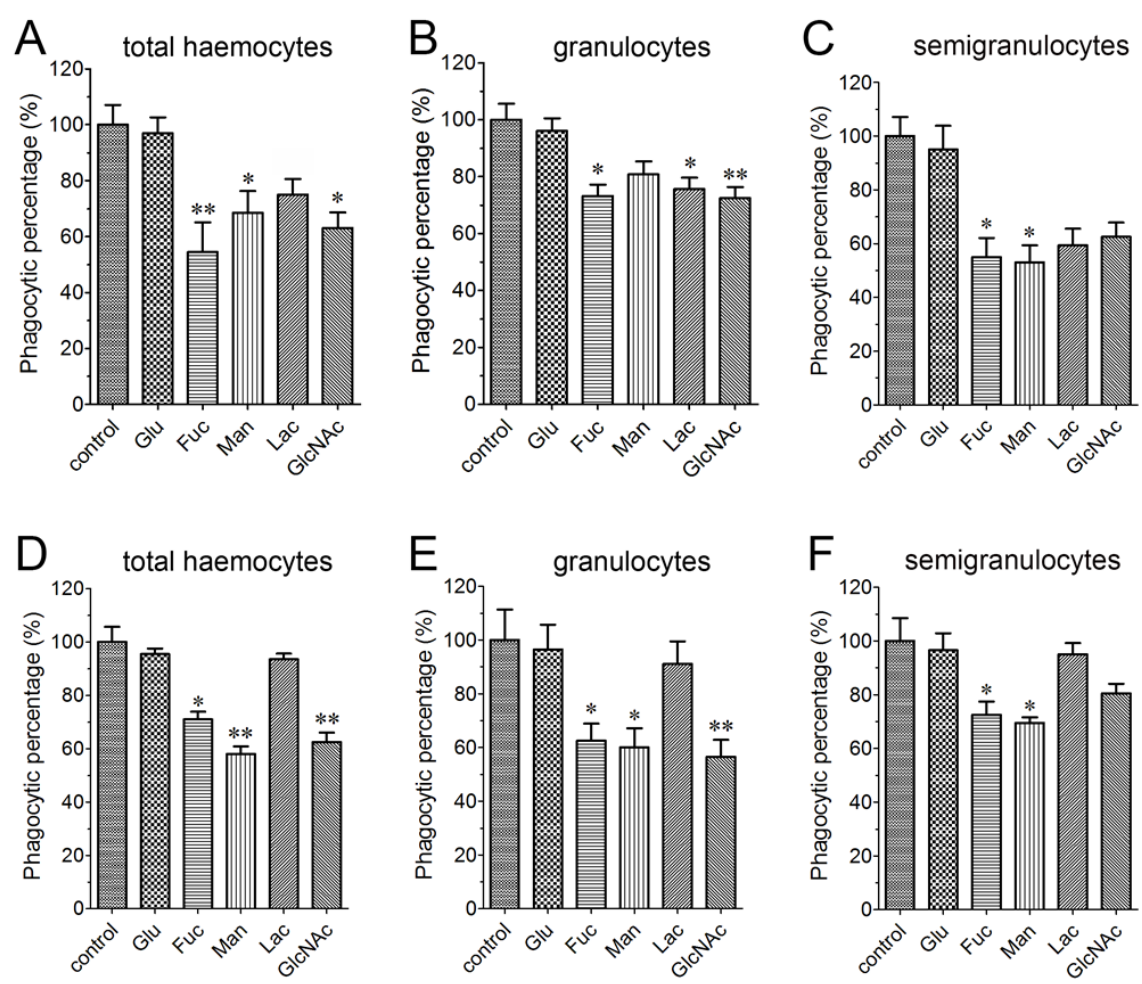

505

506

Fig. 4. Involvement of lectin-like receptors (LLRs) in the phagocytosis of different microbes.

507

Haemocytes were pre-incubated with different carbohydrates, and the phagocytic inhibitory

508

activity towards $V$. splendidus (A, B, C) and $S$. aureus (D, E, F) was determined. Results are

509

means \pm S.D. $(\mathrm{n}=6),{ }^{*} p<0.05, * * p<0.01$. 

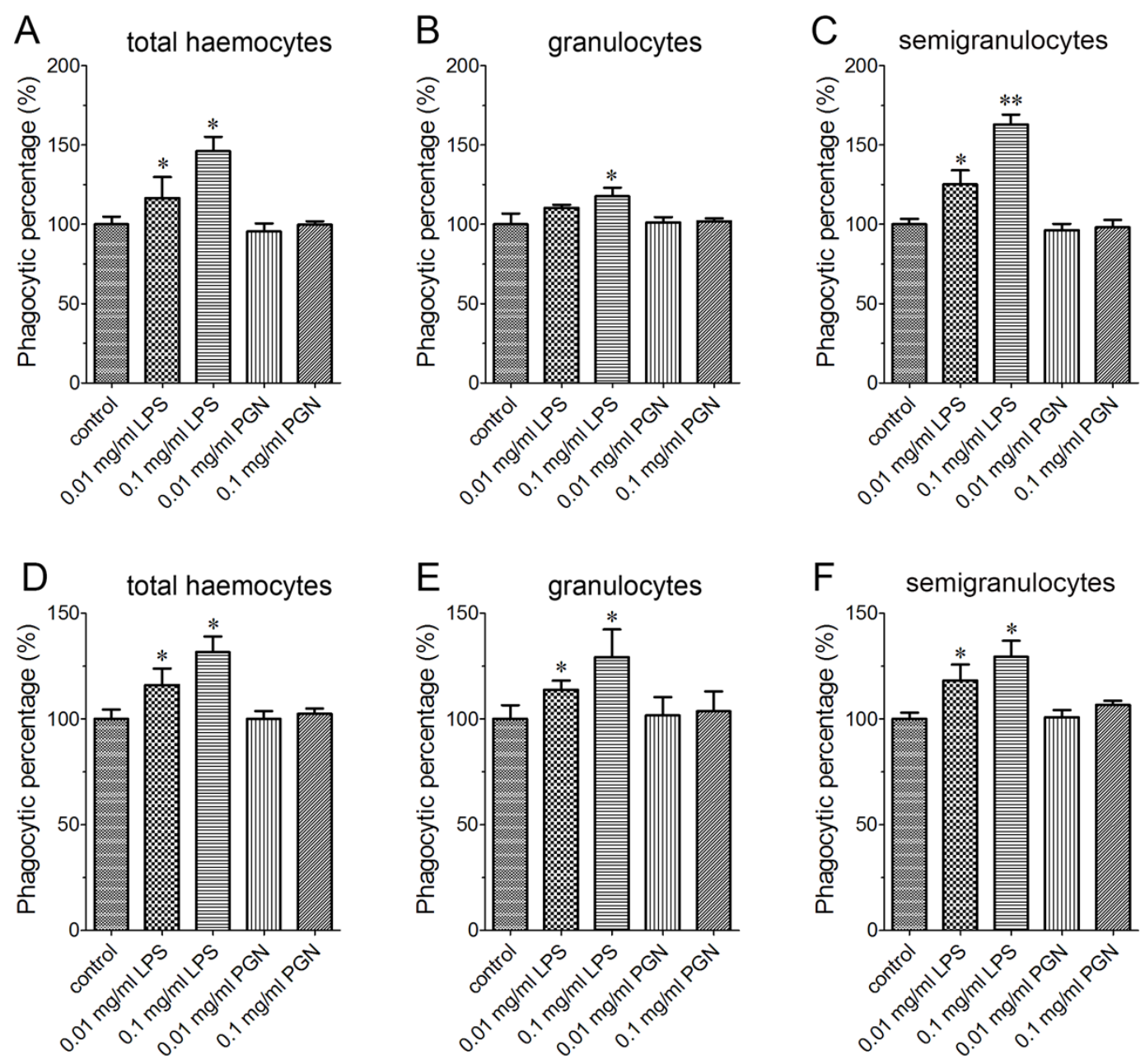

511

512 Fig. 5. Enhancement of phagocytosis after LPS treatment. Haemocytes were pre-treated with

513 LPS and PGN at different concentrations, and the phagocytic activities towards $V$. splendidus (A,

$514 \mathrm{~B}, \mathrm{C})$ and $S$. aureus (D, E, F) were determined. Results are means \pm S.D. $(\mathrm{n}=6), * p<0.05, * * p$ $515<0.01$. 
A
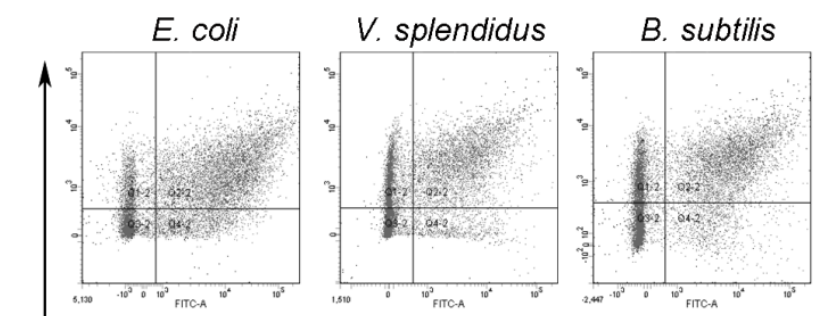

S. aureus
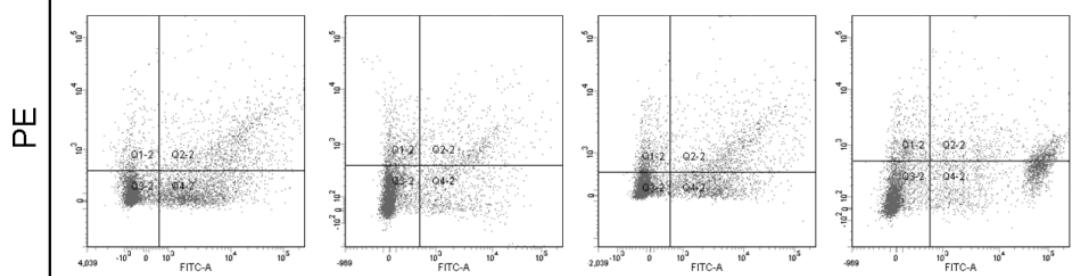

WGA
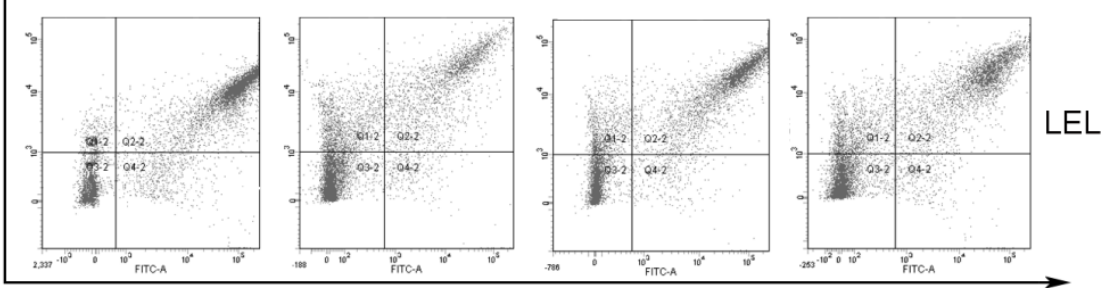

FITC

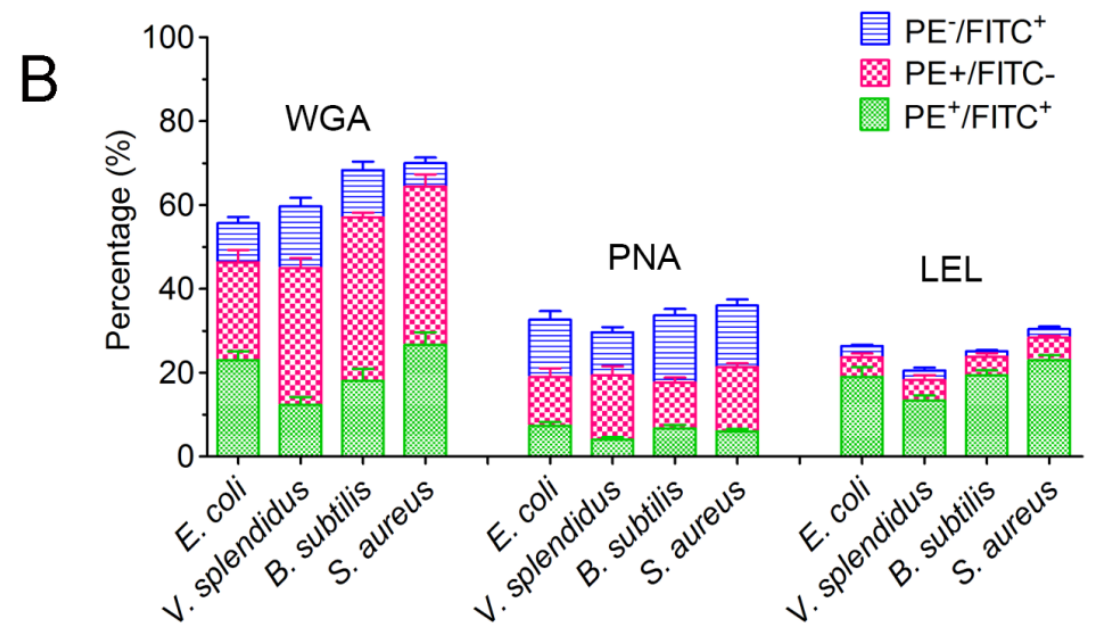

518 Fig. 6. Lectin staining analysis of the phagocytes from C. gigas. (A) Haemocytes incubated with

519 FITC-labeled E. coli, V. splendidus, S. aureus and B. subtilis, and stained with PE-labeled WGA,

520 PNA and LEL respectively. The correlation between lectin staining and phagocytes was

521 analyzed by flow cytometry. (B) Percentages of haemocytes gated on $\mathrm{PE}^{+} / \mathrm{FITC}^{+}, \mathrm{PE}^{+} / \mathrm{FITC}^{-}$and

$522 \mathrm{PE}^{-} / \mathrm{FITC}^{+}(\mathrm{n}=5)$. 


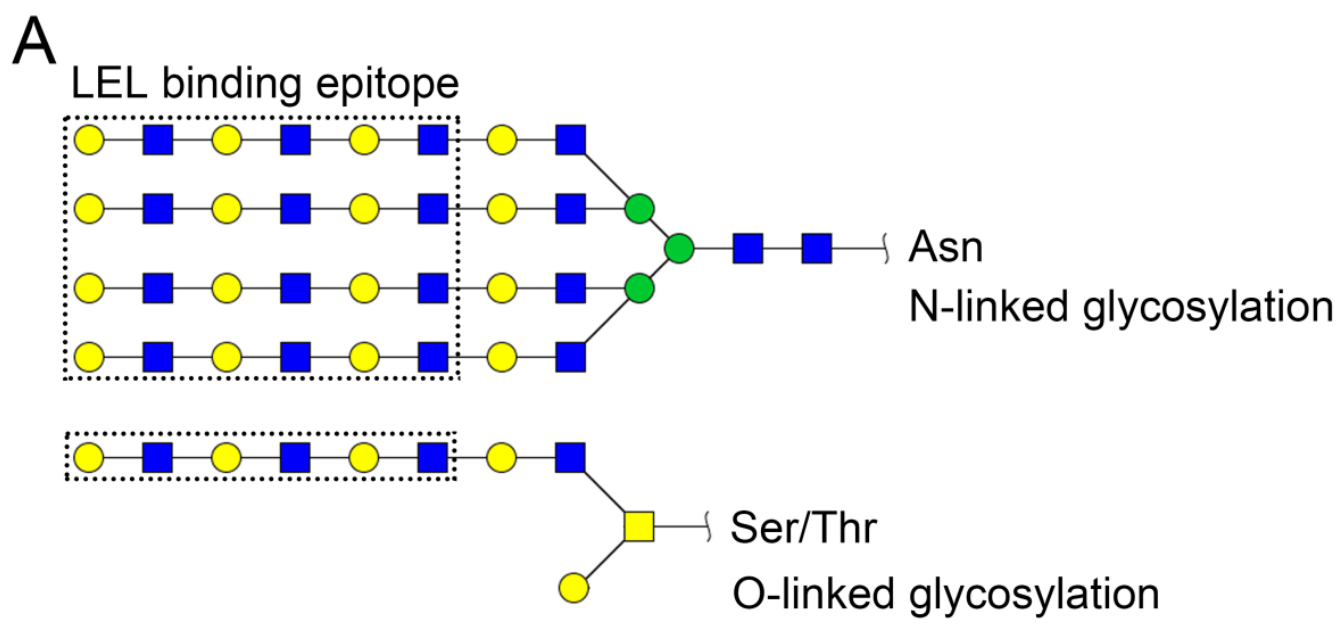

OGal $\square$ GlcNAc OMan $\square$ GalNAc

B
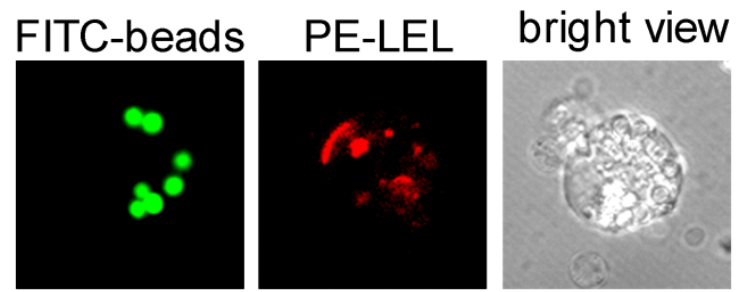

merge
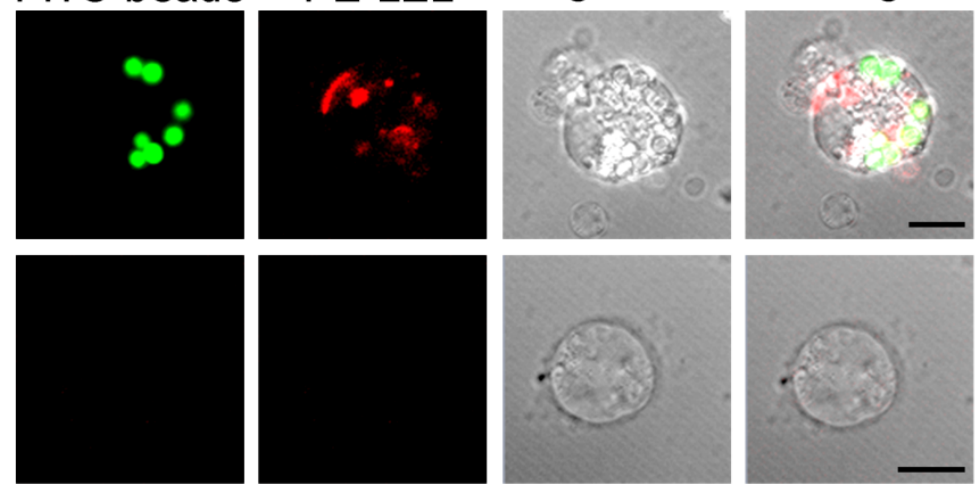

phagocyte

non-phagocytic cell

Fig. 7. LEL binding epitopes polylactosamine are indicated by dotted rectangles, and the

526 predicted carbohydrate structures are represented in $N$-linked and $O$-linked glycans (A). The

527 distribution of polylactosamine in oyster phagocytes revealed by confocal microscopy (B).

528 Haemocytes were incubated with FITC-labeled latex beads, and then fixed and permeabilized,

529 followed by PE-labeled LEL staining. A representative phagocyte and non-phagocyte are shown. 


\section{Figure 1}

Figure1

Flow cytometric analysis and May-Grunwald-Giemsa (MGG) staining of haemocytes from $C$. gigas. (A) Haemocytes were categorized into different subpopulations by flow cytometry followed by MGG staining analysis. Bar: $5 \mu \mathrm{m}$. (B) The percentages of each subpopulation were calculated with statistically analysis. Results are means \pm S.E.M. $(n=6)$.

A agranulocytes
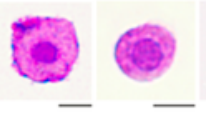

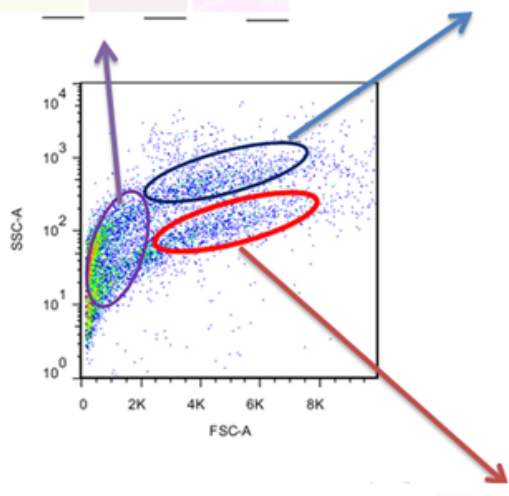

granulocytes
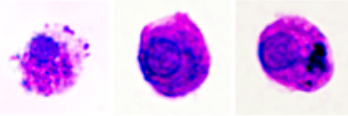

semigranulocytes

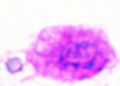

B

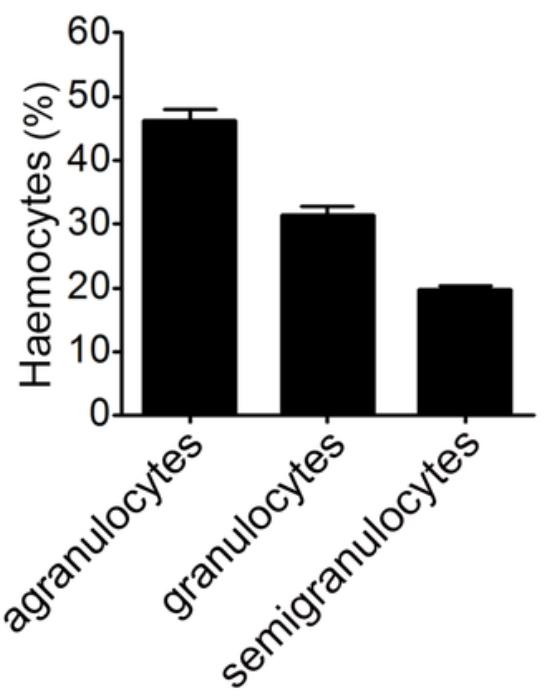




\section{Figure 2 (on next page)}

Figure2 
A phagocytes
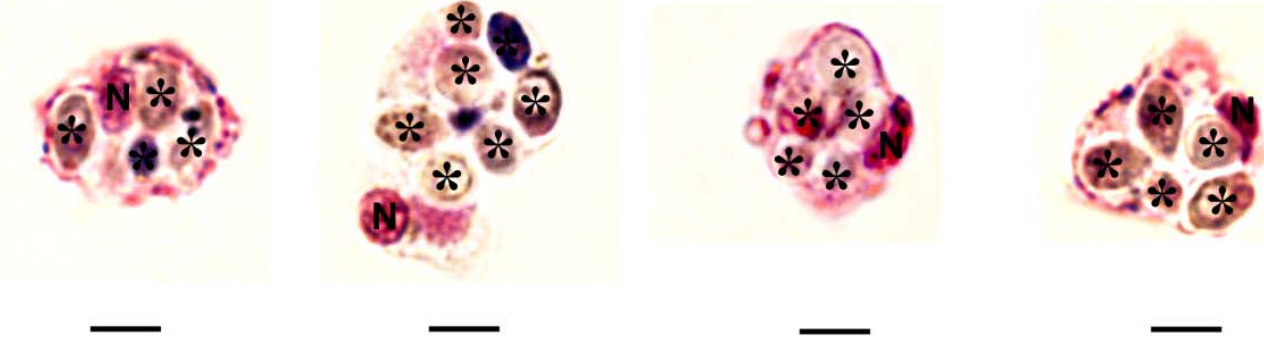

non-phagocytic haemocytes

B

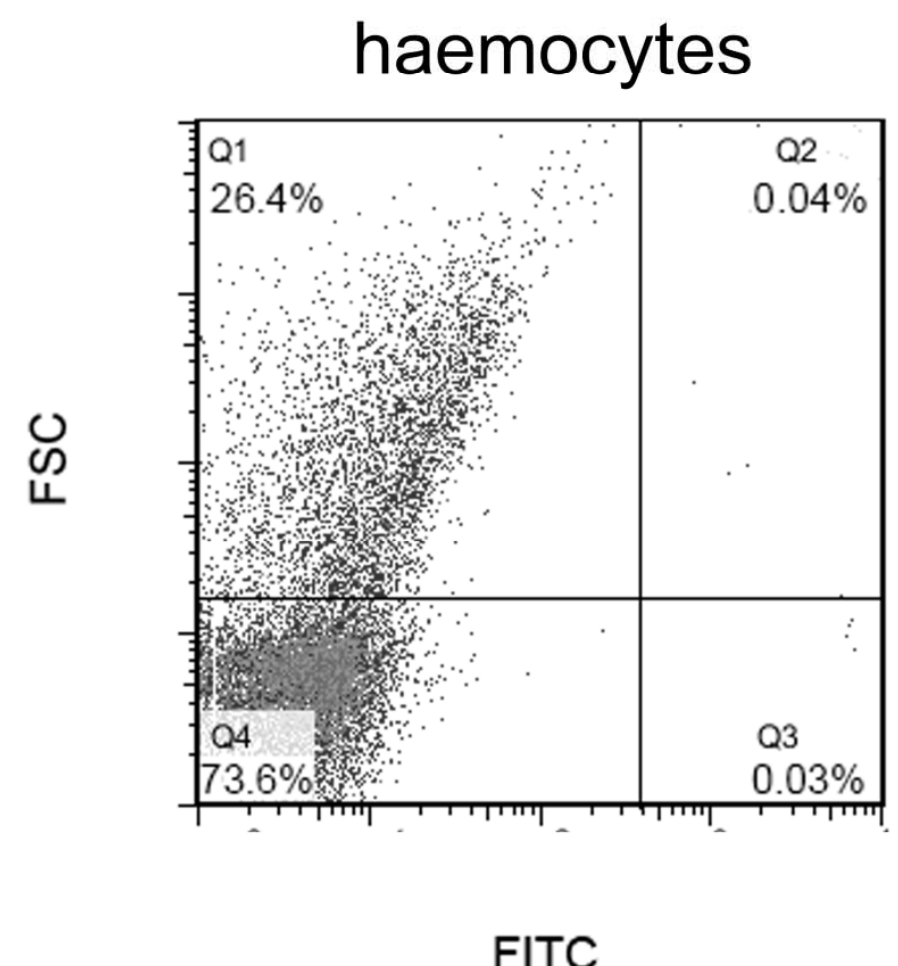

latex beads + haemocytes

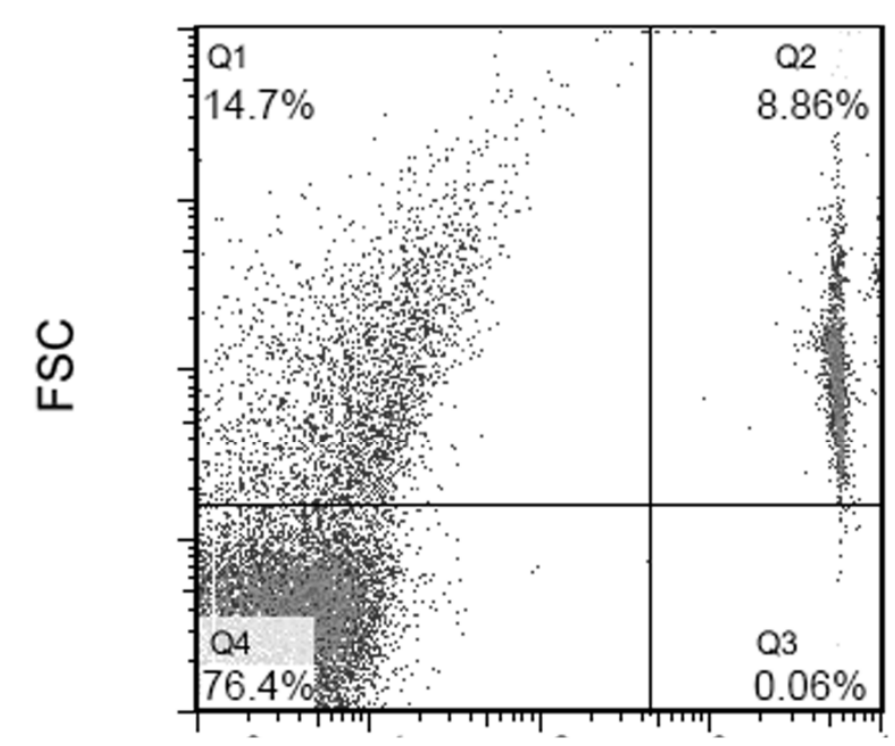

FITC 
Figure 3

Figure3 
A

E. coli

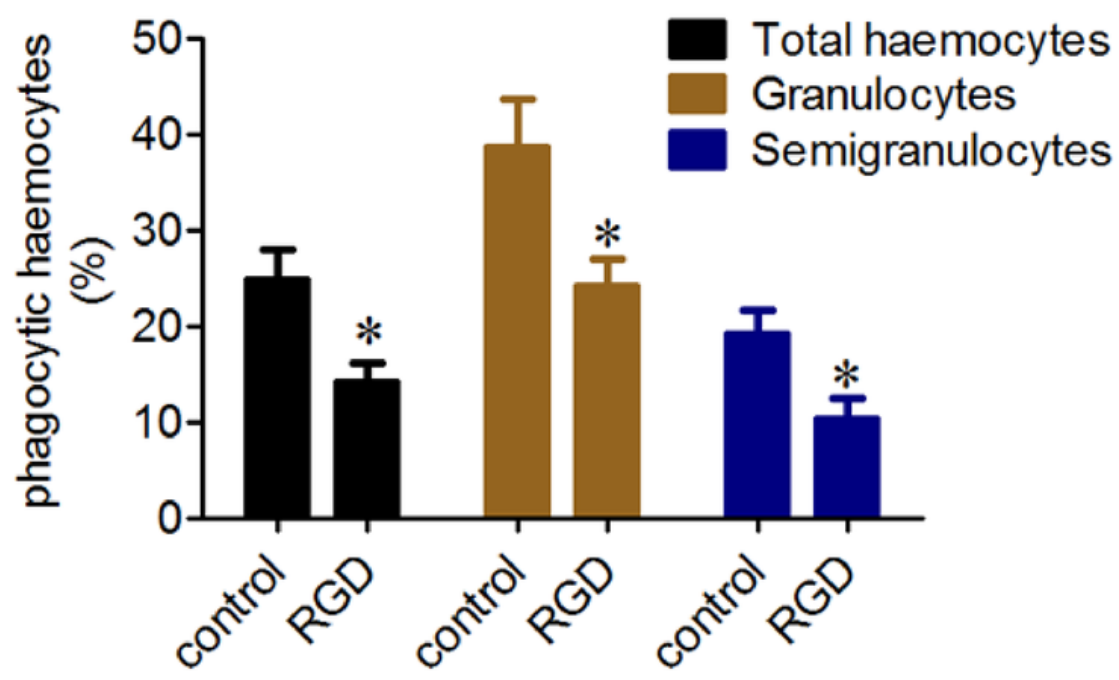

B

V. splendidus

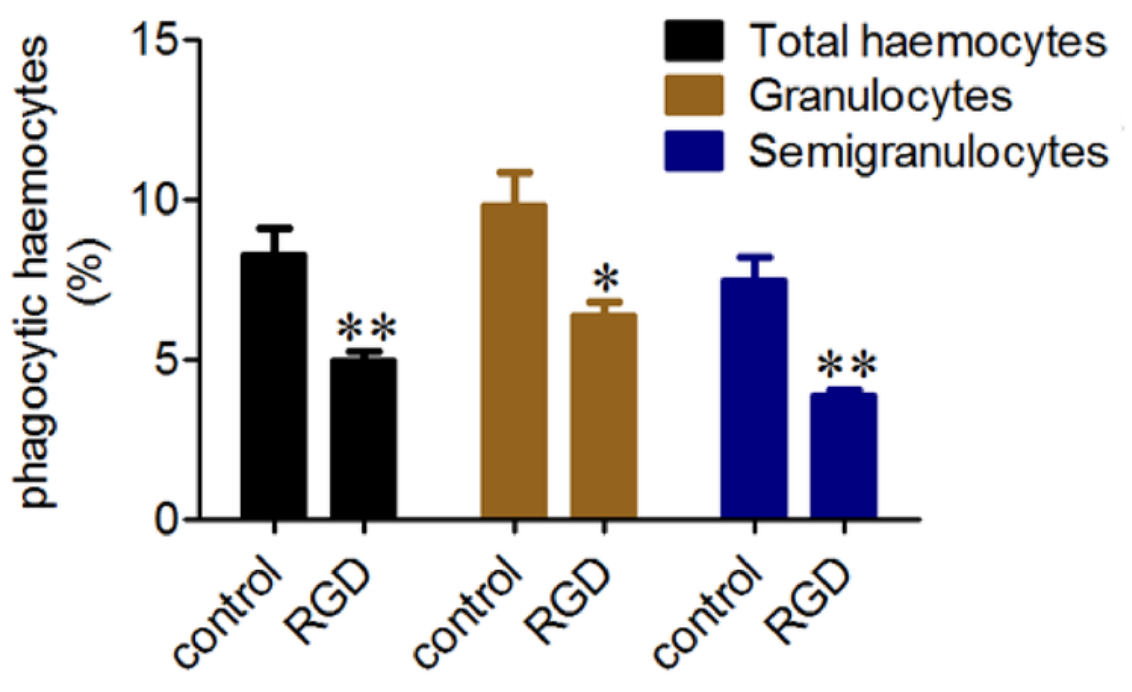

C

S. aureus

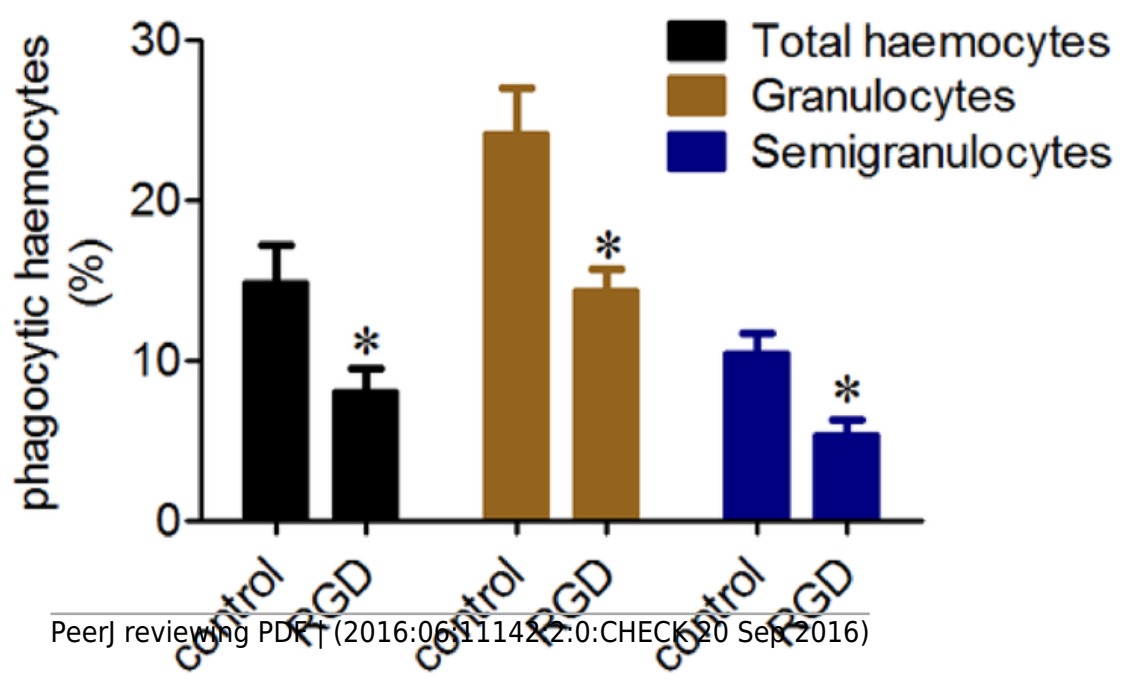


Figure 4

Figure4
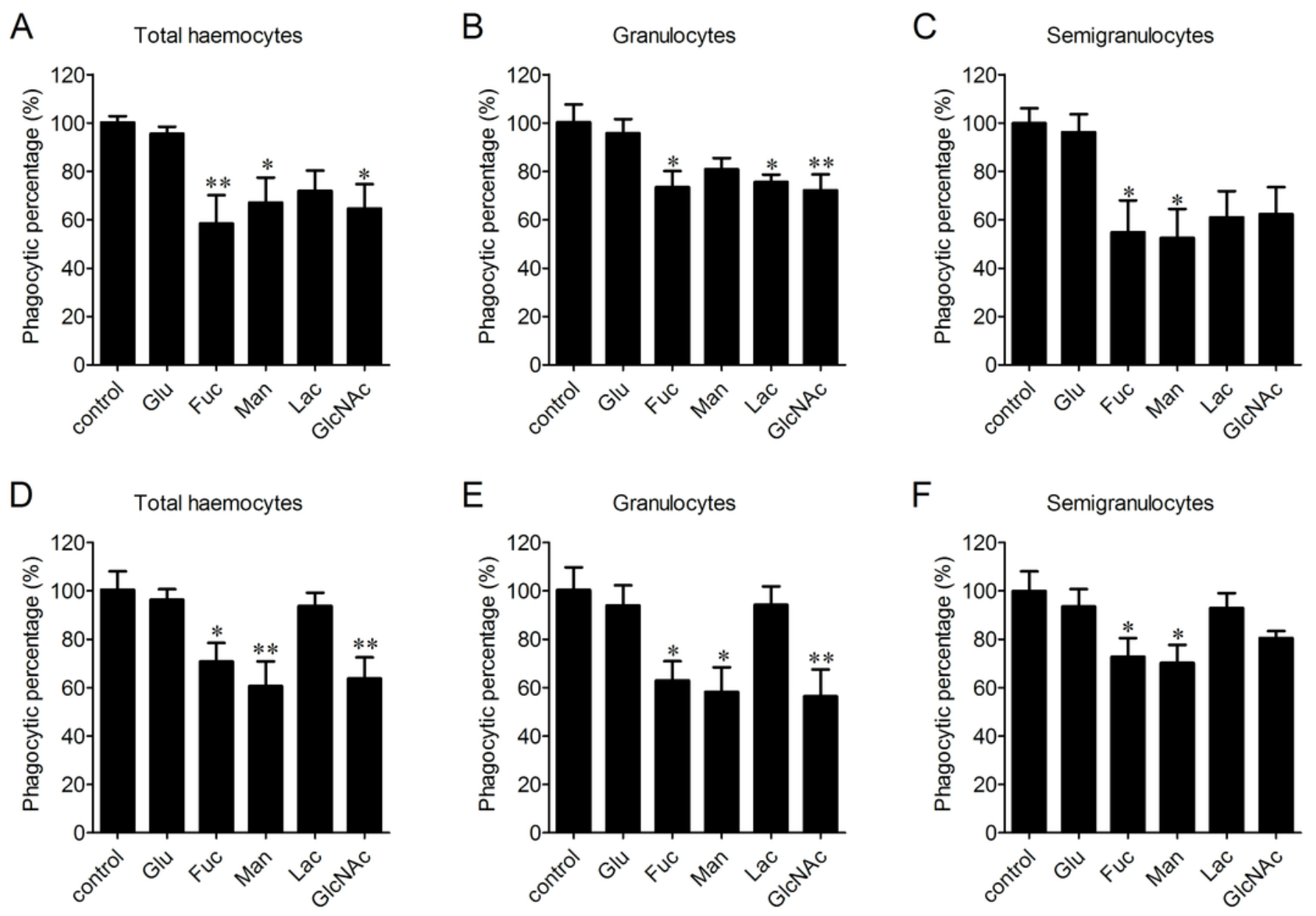
Figure 5

Figure5
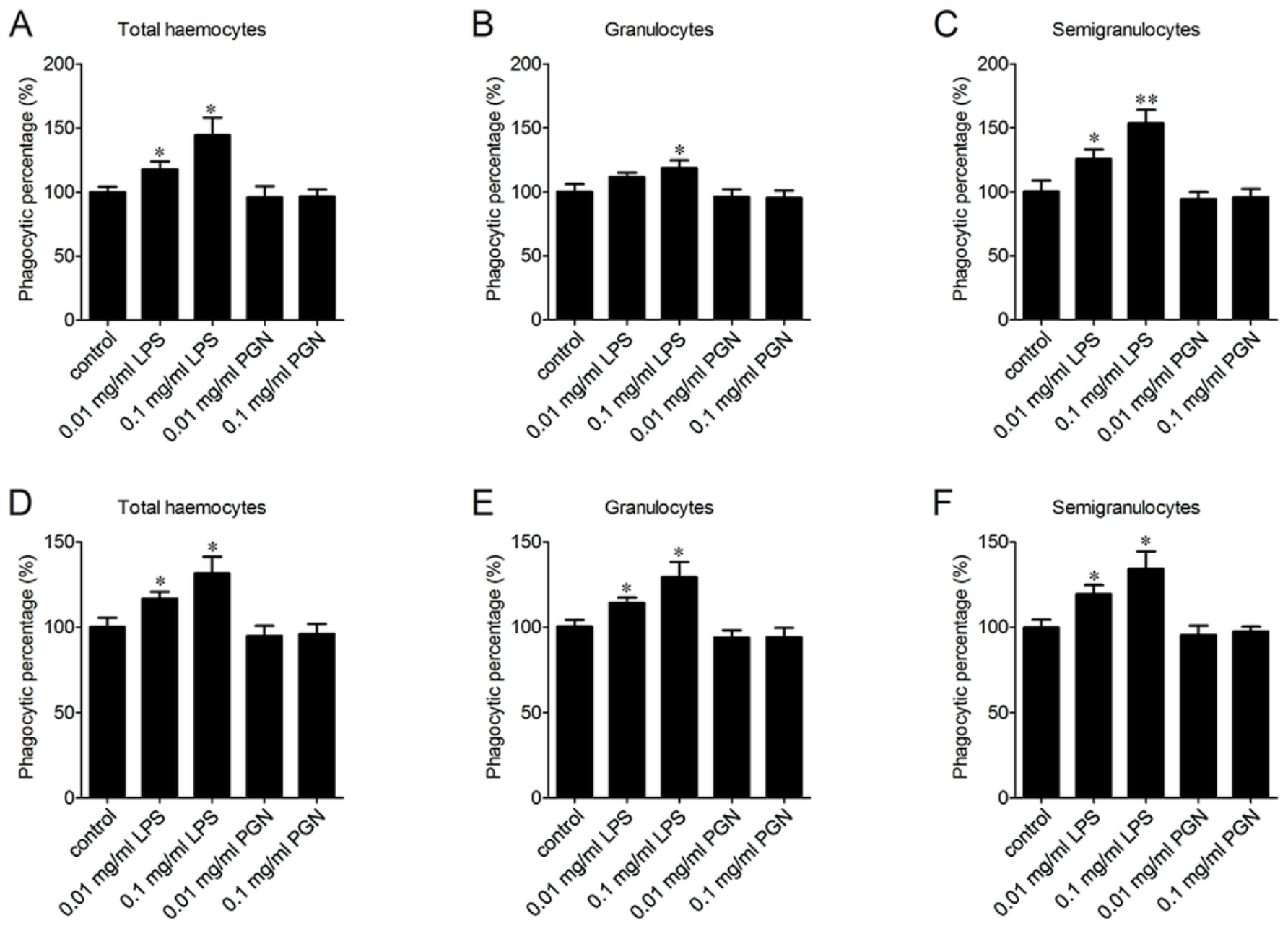
Figure 6

Figure6 
A
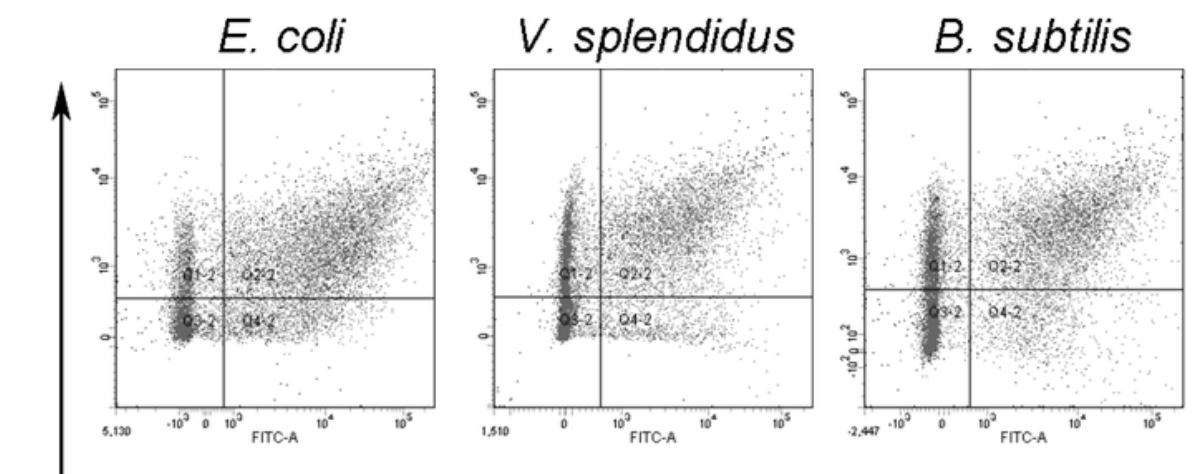

S. aureus
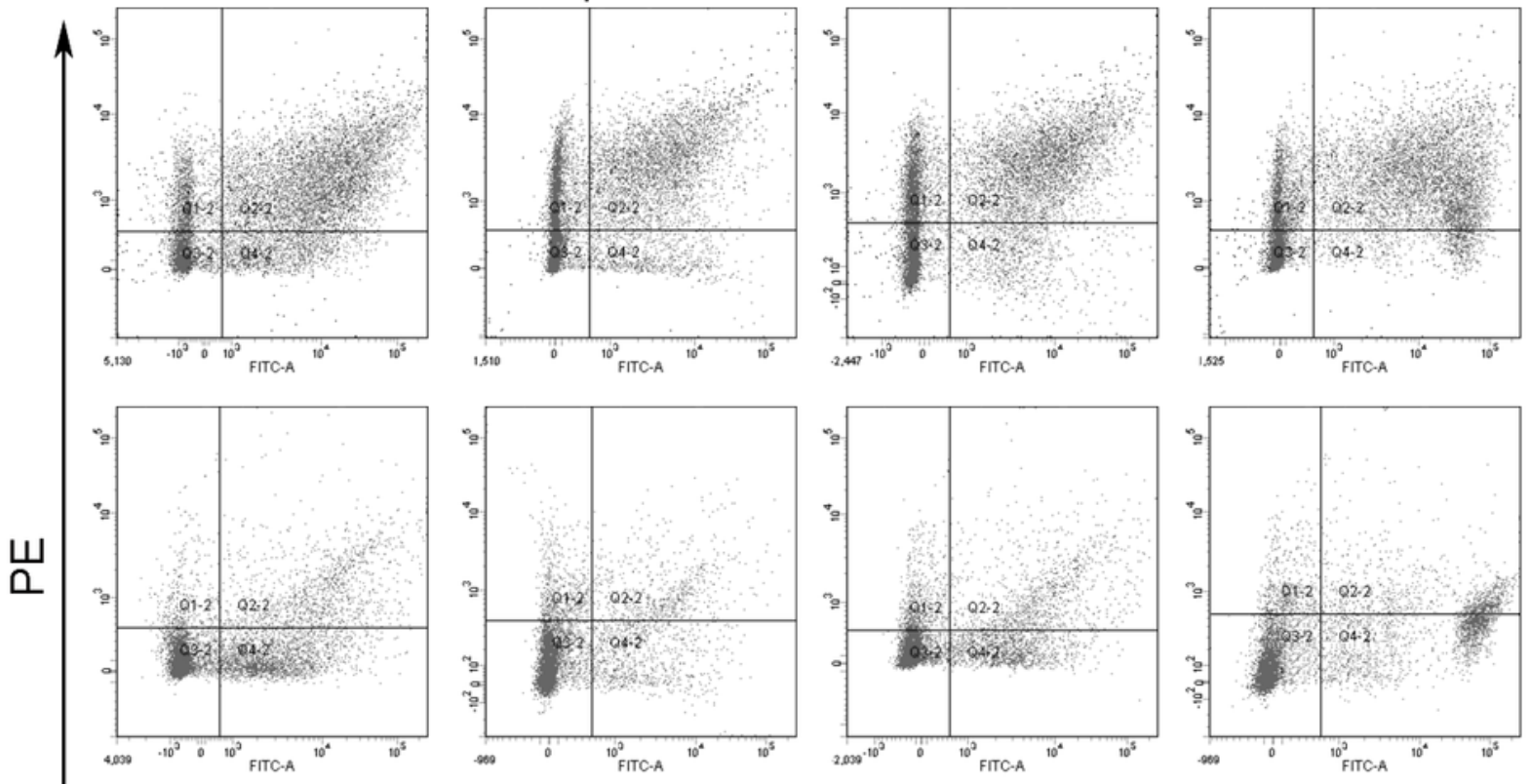

WGA
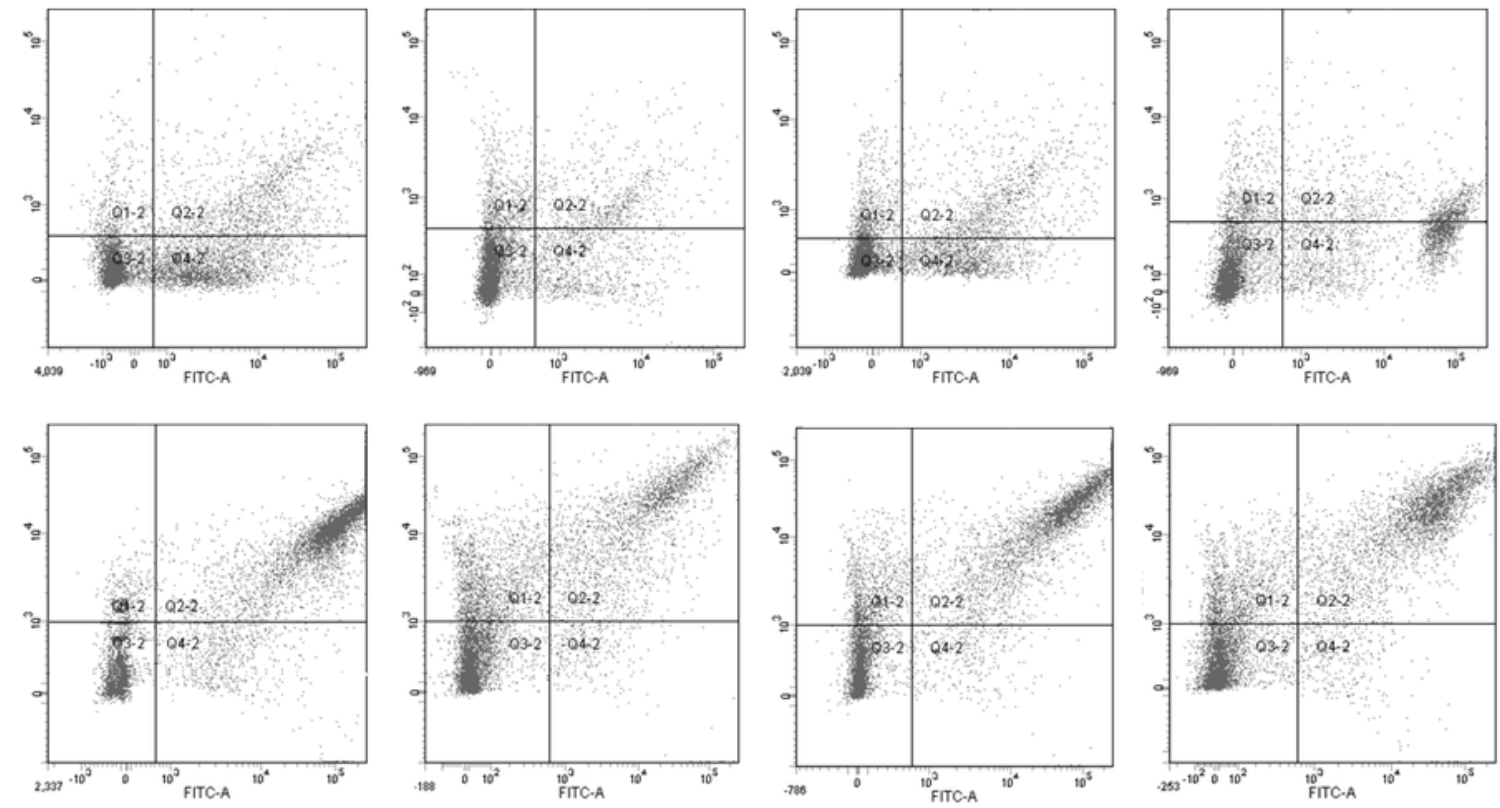

PNA

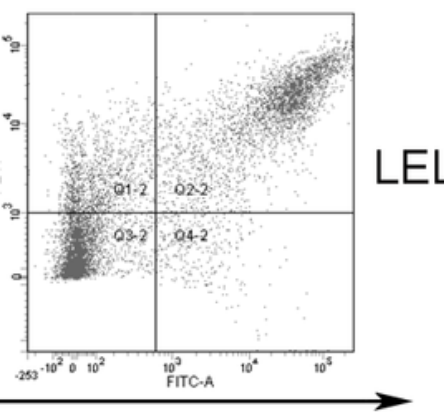

FITC

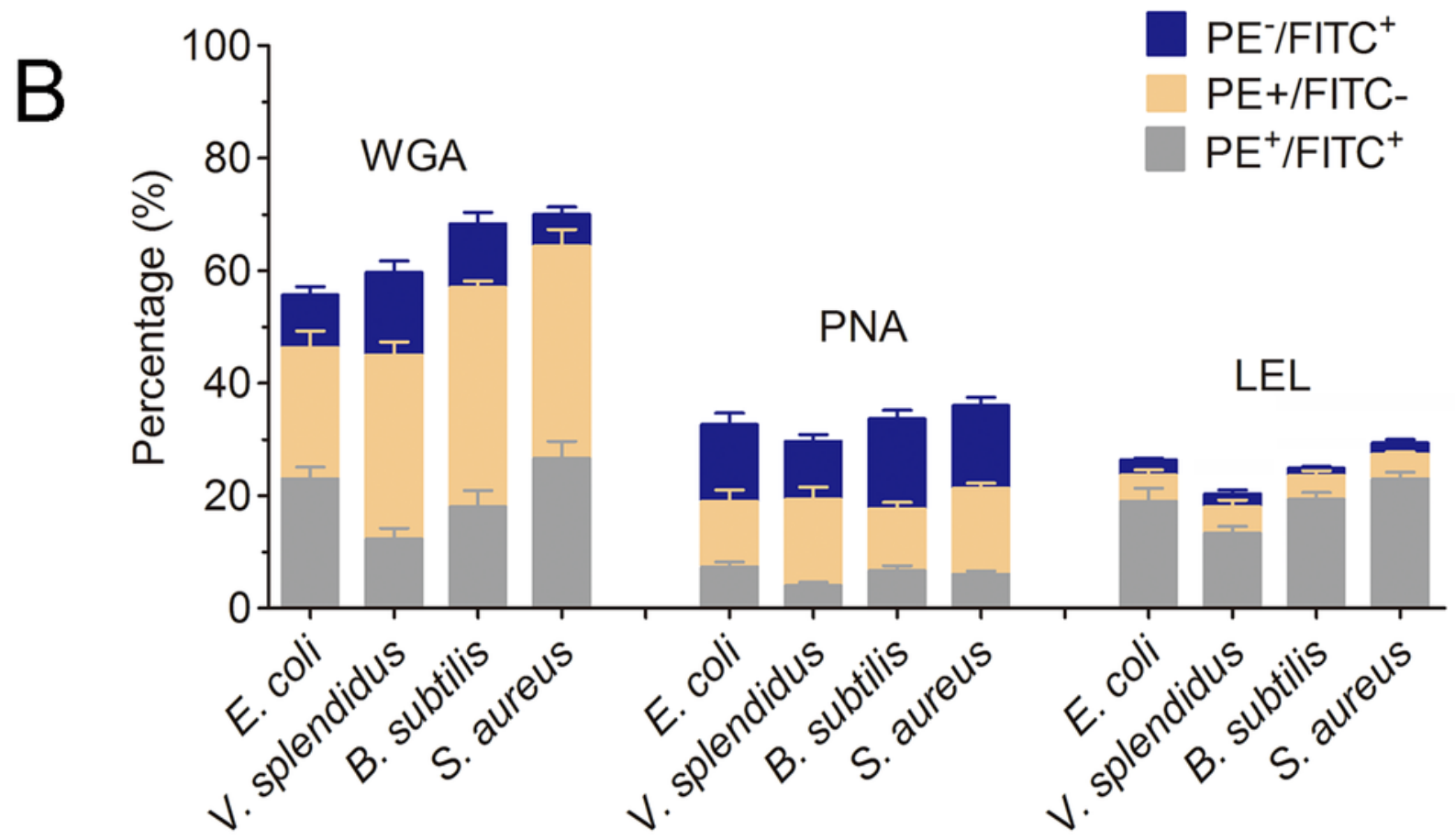




\section{Figure 7 (on next page)}

Figure7 
A

LEL binding epitope
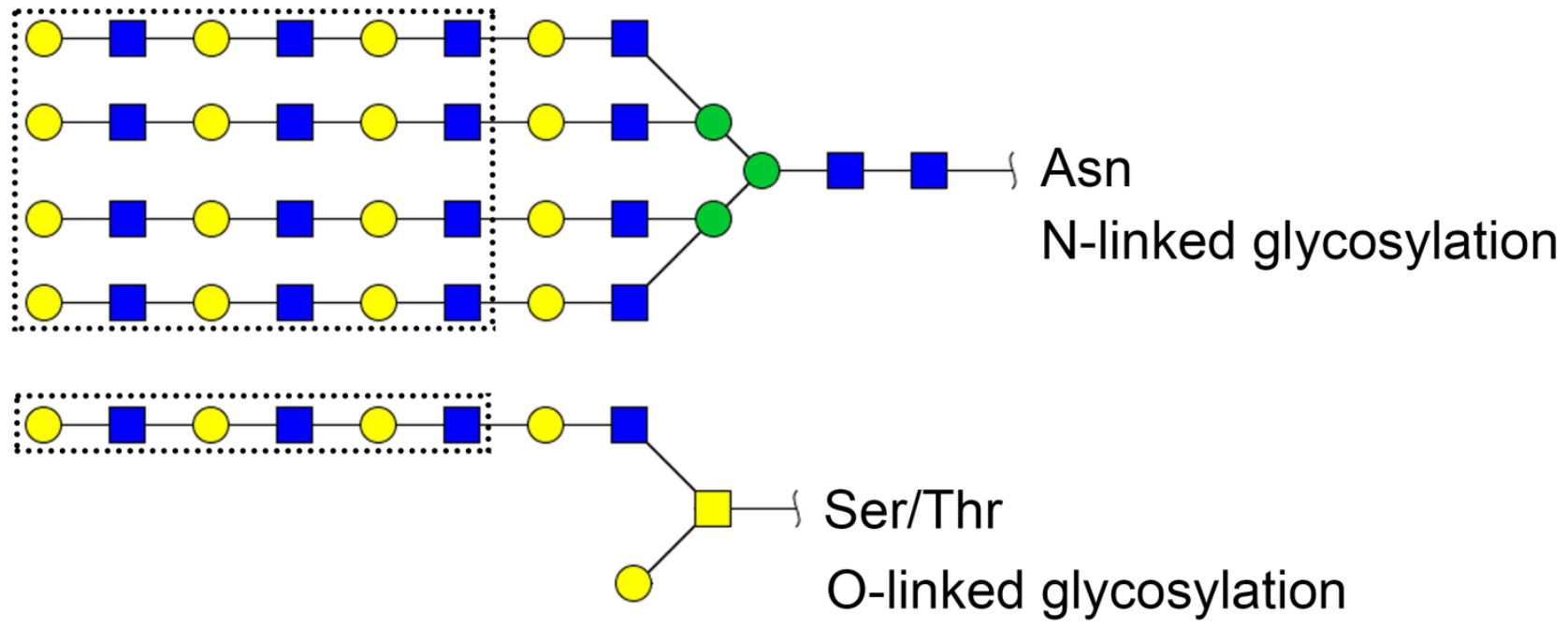

OGal $\square$ GlcNAc OMan $\square$ GalNAc

$B$

FITC-beads PE-LEL bright view merge
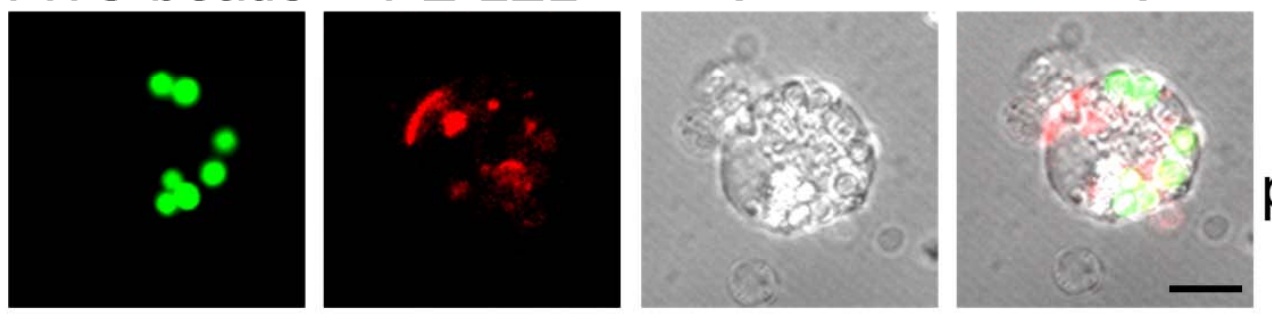

phagocyte
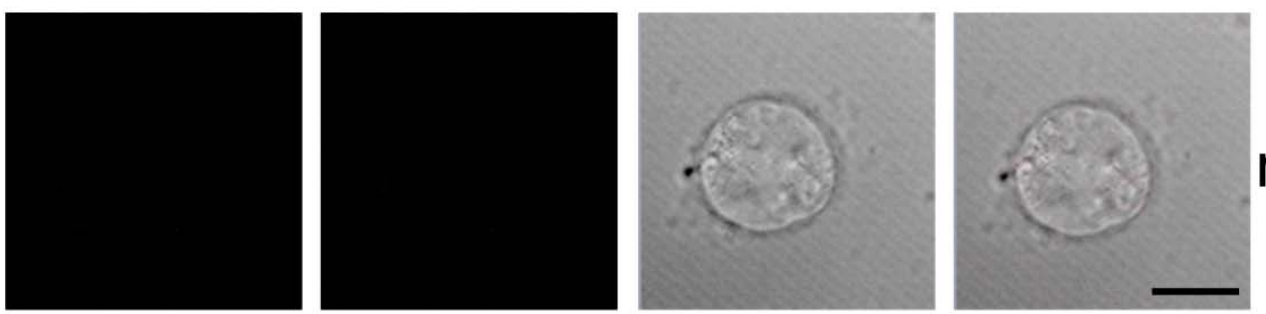

non-phagocytic cell 